University of Wollongong

Research Online

Faculty of Engineering and Information

Faculty of Engineering and Information

Sciences - Papers: Part B

Sciences

2020

Thermal features vis a vis strain features of fracturing process in jointed rock layer under concentrated load

Haiqing Yang

Bolong Liu

Shivakumar Karekal

University of Wollongong, skarekal@uow.edu.au

Follow this and additional works at: https://ro.uow.edu.au/eispapers1

Part of the Engineering Commons, and the Science and Technology Studies Commons

Research Online is the open access institutional repository for the University of Wollongong. For further information contact the UOW Library: research-pubs@uow.edu.au 


\title{
Thermal features vis a vis strain features of fracturing process in jointed rock layer under concentrated load
}

\begin{abstract}
In case of earthquakes and crustal movement, the concentration of impounding load over a large region of crust can cause disturbances to the stratum. In order to quantitatively investigate crack initiation, propagation and coalescence processes of jointed stratum based on thermal variations caused by concentrated mechanical loading, a series of indention tests were performed on granite specimens. In the experiment, fracture process and resulting infrared radiation fields of specimens were respectively recorded by synchronized digital image correlation system and infrared camera. Then, thermal characteristics of mixed shear-tensile and tensile conical crack were analyzed. Experimental results indicate that the highlighted temperature localization is mainly caused by shear deformation within the localized fracture process zone. It is shown that in the initiation process, the abnormities in the temperature concentration factors are caused by the frictional-thermal effect for mixed mode crack and the thermoelastic effect for tensile mode crack. Subsequently, in the propagation process, these two crack types followed newly proposed criteria, namely, the maximum temperature gradient criterion for mixed mode crack and the minimum temperature gradient criterion for tensile mode crack. In addition, the intensity of temperature concentrations in crack initiation stage and coalescence stage are more pronounced than that of crack propagation stage. These thermal effects strongly correlated with the stress states in the cracking process. The new findings from the infrared radiation temperature distributions improve our understanding of fracturing process of rock mass. Furthermore, it will provide some fundamental references for geophysical prospecting in jointed rock mass.
\end{abstract}

\section{Keywords}

layer, rock, thermal, features, vis, strain, fracturing, load, concentrated, jointed, under, process

\author{
Disciplines \\ Engineering | Science and Technology Studies
}

\section{Publication Details}

Yang, H., Liu, B. \& Karekal, S. (2020). Thermal features vis a vis strain features of fracturing process in jointed rock layer under concentrated load. Earth and Space Science, 1-52. 
1 Thermal features vis a vis strain features of fracturing process in jointed rock layer under concentrated load

3 Haiqing Yang ${ }^{1,2^{*}}$, Bolong Liu ${ }^{1,2}$, and Shivakumar Karekal ${ }^{3}$

$4 \quad{ }^{1}$ State key laboratory of coal mine disaster dynamics and control, Chongqing

5 University, Chongqing 400045, China.

$6 \quad{ }^{2}$ National Joint Engineering Research Center of Geohazards Prevention in the

7 Reservoir Areas, Chongqing 400045, China.

$8{ }^{3}$ School of Civil, Mining and Environmental Engineering, University of Wollongong,

9 Wollongong, NSW, Australia 2522.

10 *Corresponding author: Haiqing Yang ( yanghaiqing06@163.com;

11 yanghaiqing@,cqu.edu.cn)

$12 †$ †dditional authors: Bolong Liu(20171601009@,cqu.edu.cn), Shivakumar Karekal

\section{3 (skarekal@uow.edu.au).}

14 Key points:

15 - Indention tests were performed on the jointed rock specimens to simulate the

16 fracturing process of jointed layer

17 - The abnormities in infrared radiation fields and temperature concentration

18 factors in crack initiation processes were appropriately interpreted 
Confidential manuscript submitted to Journal of Geophysical Research: Solid Earth

19

- New thermal criteria for two types of crack propagations were proposed. 
Confidential manuscript submitted to Journal of Geophysical Research: Solid Earth

20

21

22

\section{Abstract}

In case of earthquakes and crustal movement, the concentration of impounding load over a large region of crust can cause disturbances to the stratum. In order to quantitatively investigate crack initiation, propagation and coalescence processes of jointed stratum based on thermal variations caused by concentrated mechanical loading, a series of indention tests were performed on granite specimens. In the experiment, fracture process and resulting infrared radiation fields of specimens were respectively recorded by synchronized digital image correlation system and infrared camera. Then, thermal characteristics of mixed shear-tensile and tensile conical crack were analyzed. Experimental results indicate that the highlighted temperature localization is mainly caused by shear deformation within the localized fracture process zone. It is shown that in the initiation process, the abnormities in the temperature concentration factors are caused by the frictional-thermal effect for mixed mode crack and the thermoelastic effect for tensile mode crack. Subsequently, in the propagation process, these two crack types followed newly proposed criteria, namely, the maximum temperature gradient criterion for mixed mode crack and the minimum temperature gradient criterion for tensile mode crack. In addition, the intensity of temperature concentrations in crack initiation stage and coalescence stage are more pronounced than that of crack propagation stage. These thermal effects strongly correlated with the stress states in the cracking process. The new findings from the 
Confidential manuscript submitted to Journal of Geophysical Research: Solid Earth

40 infrared radiation temperature distributions improve our understanding of fracturing

41 process of rock mass. Furthermore, it will provide some fundamental references for

42 geophysical prospecting in jointed rock mass.

43

\section{Introduction}

Thermal effects are commonly encountered in geological processes, such as neo-tectonic, active fault, earthquakes, landslides and volcanic eruptions. According to the thermal anomalies, the location and characteristics of geological activities can be determined in geophysical prospecting ( $\mathrm{Lu}$ et al. 2016; Tramutoli et al., 2013; Xiong et al. 2015). In jointed stratum, the concentrated load caused by hills, dam and reservoirs et al. may lead to the fracture of crust, causing the instability of formation and even the secondary disaster, such as reservoir-induced seismicity (Ramasamy et al., 2019; Stiros \& Pytharouli, 2018). Consequently, it is pressing to investigate the fracture process in jointed stratum from thermal perspective. As a result, the failure of layer can be detected.

The thermal mechanism of stratum under the loading of tectonic activity has been a longstanding topic in geoscience. For the earthquake, Milne (1886) initially found the temperature changes before large earthquakes. Generally, it is acknowledged that the increase in temperature of a fault mainly caused by shear heating in geoscience (Li et al. 2015). Subsequently, according to the in situ measurements and theories of thermodynamics and heat conduction effect, Chen et al. $(2013,2016)$ also found that 
60 the change in bedrock temperature is accordant with stress adjustment in seismogenic

61 tectonics. Therefore, stress state of bedrock during the earthquake can be detected

62 based on the temperature change. In active fault zone, temperature of the rock varies

63 due to the internal deformation of thrust belts and shear heating under the loading

64 (Bosea \& Mukherjee, 2020; Long et al, 2011; Mukherjee, S. 2017). In detail, internal

65 deformation of thrust sheets generally occurs in the forms of layer (or thrust)-parallel

66 simple shear and layer (or thrust)-normal pure shear (Sanderson, 1982), leading to the

67 high temperature. Shear heating is caused by the sliding of one rock unit over the

68 other along fault planes, especially in reverse faulting. Graham and England (1976)

69 initially pointed out that the obvious temperature increase in faulted hangingwall and

70 footwall blocks generally occurs in fault zone with high the slip rate and rock strength.

71 Furthermore, Mukherjee (2017) found that the coefficient of friction, density and

72 thickness of the hangingwall block havelinear correlation with shear heating. Through

73 theoretical investigation on kinematics and shear heat pattern of ductile simple shear

74 zones, Mulchrone1 \& Mukherjee (2016) drawn a conclusion that the maximum

75 temperature in shear zones occurs at either boundaries of the shear zone or equidistant

76 from them. However, the thermal characteristics and mechanisms in jointed rock

77 under the concentrated load have scarcely studied in the past.

78 As the temperature can be detected by infrared camera, some scholars tried to

79 investigate the stress state and failure process of loaded rock through infrared 80 radiation temperature fields, infrared radiation mechanisms of rock were 
Confidential manuscript submitted to Journal of Geophysical Research: Solid Earth

81 simultaneously revealed. Initially, the evolution of infrared thermograms of rocks in

82 the failure process was observed by some researchers. For example, Wu et al. (2006a)

83 conducted a series of tests on rock under uniaxial stress, compressive shear, biaxial

84 stress, frictional slide and impact. It is found that highlighted infrared radiation

85 temperature (IRT) is prone to appear at fracturing center of compressively loaded rock

86 and shear zone. Therefore, the thermoelastic effect and the frictional-thermal effect

87 are main mechanisms that cause the infrared radiation image abnormalities.

88 Subsequently, on the basis of the infrared thermograms, IRT fields were quantitatively

89 investigated. Wu et al. (2006b) further studied IRT fields of rock under uniaxial and

90 biaxial load and compressive shear. Several IRT abnormalities were summarized on

91 the basis of the average infrared radiation temperature (AIRT) curves, which can be

92 seen as precursors for rock fracturing and failure. Li et al. (2018) researched the

93 precursor information of coal and rock failure through the maximum IRT and AIRT

94 curves. After the main rupture of the sample, it was found that the maximum ITR

95 increased dramatically, while AIRT curves show obvious hysteresis in reaching the

96 first peak value after the main rapture. For jointed rock with different fissure angles,

97 Cheng et al. (2018) found that the effect of fissure angle on the maximum IRT and

98 AIRT is similar with that on the normal load. The changes of the maximum IRT and

99 AIRT simultaneously reach the peak value when fissure angle is $60 \mathrm{deg}$. Furthermore,

100 the relationship between stress state of rock and IRT during the loading was explored.

101 Nevertheless, previous studies normally focused on the whole IRT fields of rock 
Confidential manuscript submitted to Journal of Geophysical Research: Solid Earth

102 under the loading, the aforementioned quantitative indices reflect the overall change

103 of rock surface. Thermal characteristics of rock at the local area such as the crack tips

104 and trajectories of cracks in the fracture process are still unclear.

105 In the present study, a series of indention test were conducted on jointed rock

106 specimens to investigate the thermal effects of jointed layer under concentrated load.

107 During the test, strain and IRT fields of specimens were recorded by digital image

108 correlation (DIC) system and infrared camera, respectively. Subsequently, comparison

109 between strain and IRT fields were undertaken. Unlike the previous investigation, a

110 new understanding on the IRT mechanism of jointed rock is presented. In addition,

111 new thermal criteria for crack propagation were proposed for different crack types

112 based on the maximum temperature gradient and the minimum temperature gradient.

113 Besides revealing crack initiation, propagation and coalescence processes, and

114 temperature concentration effects of jointed rock layer.

1152 Experimental Methodology

117 Granite block collected from Hunan province, China was employed in the present

118 experiment in view of its high sensitivity to temperature under mechanical loading.

119 The granite was cut into 3 blocks with the dimension of $200 \mathrm{~mm} \times 140 \mathrm{~mm} \times 30 \mathrm{~mm}$, as

120 shown in Figure 1. According to the research conducted by Johnson (1985), the ratio

121 of the specimen width to plastic zone depth should be larger than 6 in order to 
Confidential manuscript submitted to Journal of Geophysical Research: Solid Earth

122 eliminate the size effect in indentation experiments. Besides, Alehoseein et al. (2000)

123 have pointed out that the plastic zone depths of the granite is $2 \mathrm{~mm}$. The minimum

124 ratio of the width to plastic zone depth is 15 , which is much more than 6 . Karekal

125 (2000) further pointed out that the depth of plastic zone is function of rock brittleness

126 and he proposed new equations considering strain softening behavior of rocks.

127 Therefore, the dimensions of specimens are reasonable. To fabricate the jointed rock

128 mass similar to that in the nature, rock mass samples were made on the basis of

129 method proposed by Yang et al. (2018a, b) and Zhao et al. (2019). In detail, 4 through

130 going cuts were made in granite block with the aid of water jet. The inclination and

131 spacing of flaws are $30 \mathrm{deg}$ (from horizontal plane) and $50 \mathrm{~mm}$, respectively. Then,

132 the cuts were filled with cement mortar, which is made of $32.5 \mathrm{R}$ cement, sand, water

133 and water reducer. Through several tests, it was found that the properties of cement

134 mortar with mass ratio of 1: 1.5: 0.4: 0.15 were well accorded with that of joint plane

135 in nature. Subsequently, specimens were maintained in the standard circumstance for

13628 days to achieve the expected bonding strength. After that, the specimens were

137 grinded and polished. For the purpose of avoiding the influence of pore water on

138 temperature response under the loading, all specimens were dried in an oven at $50^{\circ} \mathrm{C}$

139 for 24 hours, then they were placed in a desiccator for cooling. During the experiment,

140 deformation on the surface of jointed rock mass is measured by DIC system. As the

141 displacement of rock surface is calculated by tracing random speckles on the

142 specimens in DIC technique (Sutton et al. 2009; Munoz et al. 2016a), white paint was 
Confidential manuscript submitted to Journal of Geophysical Research: Solid Earth

143 firstly painted on the front surface of specimens to make a basecoat. Then, black paint

144 was sprayed randomly. After several treatments mentioned above, jointed rock

145 specimens were evenly fabricated. Properties of granite and jointed plane are listed in

146 Table 1.

148 Test apparatus employed in the present study consists of loading system, control

149 system, XTDIC-2D system, D384M infrared camera and isolating box, as shown in

150 Figure 2.

151 In detail, loading system is comprised of a MTS servo-hydraulic machine and a pair

152 of locally designed indenters. The loading capacity of both vertical and horizontal

153 cylinders installed in MTS servo-hydraulic machine is $600 \mathrm{kN}$ and theirs full cylinder

154 stroke is $100 \mathrm{~mm}$. A pair of indenters with spacing of $60 \mathrm{~mm}$ and tip width of $12 \mathrm{~mm}$

155 is installed on the vertical platens to generate concentrated load on the fabricated rock

156 mass specimen. Indenters are made of H13 steel with hardness of 55 HRC. The

157 deformation of indenters under loading can be ignored when compared to the

158 deformation of the fabricated rock mass. The loading rate of the actuators

$159(0.001-10 \mathrm{~mm} / \mathrm{min}$ or $0.1-100 \mathrm{kN} / \mathrm{min})$ is controlled by the MTS console.

160 The deformation of rock block during the loading is captured by XTDIC-2D which is

161 a non-contact deformation measurement system. The measurement system consists of

162 a Basler acA2440-75um charge coupled device (CCD) camera and a Light-Emitting 
Confidential manuscript submitted to Journal of Geophysical Research: Solid Earth

163 Diode (LED) light with luminous flux of $18000 \mathrm{~lm}$. The CCD camera has a resolution

164 of $2448 \times 2048$ pixels and a frame rate of $75 \mathrm{fps}$. As light spectrum of LED illuminant

165 does not contain infrared, IRT of jointed rock mass specimens is not affected by LED

166 light (Liu et al. 2018). The field of view and accuracy of XTDIC-2D system is 10

$167 \mathrm{~m} \times 10 \mathrm{~m}$ and 0.01 pixel, respectively.

168 D384M infrared camera is used to measure the IRT of the rock surface in the

169 experiment. The specifications of D384M are as follows: resolution, $384 \times 288$ pixels;

170 noise-equivalent temperature difference, $0.045 \mathrm{~K}$, frame rate, $12 \mathrm{fps}$; temperature

171 range, $-20-150 \mathrm{degC}, 100-650 \mathrm{degC}$; field of view, $28.4^{\circ} \times 21.5^{\circ}$; spectral range, $8-14$

$172 \mu \mathrm{m}$. In addition, to eliminate the influence of environmental interference, an isolating

173 box with $1.5 \mathrm{~m}$ in length, $0.3 \mathrm{~m}$ in width and height is prepared (Sun et al. 2017). The

174 isolating box is made of cystosepiment, which provide good heat insulation.

176 In the present investigation, a series of indention tests were performed on the jointed

177 rock mass specimens to simulate the cracking process of jointed rock layer under the

178 concentrated load. Detailed experimental procedures are as follows:

179 (1) Specimens were firstly placed in laboratory for over 24 hours, thus the

180 temperature of jointed rock specimens is equal to room temperature (Li et al. 2018,

181 Ma \& Sun, 2018). In order to reduce the end friction between the specimen and

182 platens, the side and bottom of specimens were lubricated by silicon grease prior to 
Confidential manuscript submitted to Journal of Geophysical Research: Solid Earth

183 loading.

184 (2) The specimen is placed in the isolating box, CCD camera and D384M infrared

185 camera lie $0.8 \mathrm{~m}$ away from the front and back of specimens, respectively.

186 (3) Before loading, a horizontal uniform load of $8.4 \mathrm{kN}$ was applied on the side

187 surfaces of specimen, which represents the confining stress of $2 \mathrm{MPa}$ in underground.

188 Then the specimen is preloaded with vertical load of $1 \mathrm{kN}$ for 10 min until no further

189 surface deformation is observed in the granite block. Infrared camera was kept in 'on'

190 mode well in advance in order to monitor the IRT field of specimen until it stabilizes.

191 (4) The vertical cylinder in MTS servo-hydraulic universal machine, CCD camera and

192 infrared camera were manually triggered simultaneously. Time intervals of triggering

193 these systems keep within 0.5 s. In the indention process, the vertical cylinder is

194 controlled in displacement manner with loading rate of $0.5 \mathrm{~mm} / \mathrm{min}$. Normal force

195 and penetration depth were measured by sensors in MTS servo-hydraulic machine in

196 real time. Horizontal confining stress was kept constant at a value of $2 \mathrm{MPa}$. The

197 frame rate of CCD camera is set to $1 \mathrm{~Hz}$. Infrared radiation video was recorded by

198 infrared camera in time.

199 (5) The experiment was terminated when penetration depth reached $10 \mathrm{~mm}$.

200 In addition, to further reduce the environment interference, personnel walking around

201 experimental rig was forbidden in the laboratory. 
Confidential manuscript submitted to Journal of Geophysical Research: Solid Earth

202

203

204

205

206 tests were segregated.

207 Data analysis involved calculation and analysis of both the strain fields and the 208 differential infrared thermograms of jointed granite block. In consideration of the 209 advantages of reducing environmental interference and uneven emissivity of the rock 210 sample surface, the differential thermograms were calculated to analyze the thermal 211 characteristics of rock samples. The method for calculating differential thermograms 212 is illustrated in Figure 3. The infrared thermograms at any time can be obtained using

213 D384M software. The thermogram is comprised of an IRT matrix of size of $288 \times 384$, 214 and is expressed as $\operatorname{IRT}_{384 \times 288}^{(1)}$. Then the valid matrix $\operatorname{IRT}_{m \times n}^{(1)}$ was selected from $215 \operatorname{IRT}_{384 \times 288}^{(1)}$ using MATLAB code to correspond to IRT of the rock surface at particular 216 location and time. Similarly, a valid matrix at initial time can be obtained, which is 217 expressed as $\operatorname{IRT}_{m \times n}^{(0)}$. By subtracting $\operatorname{IRT}_{m \times n}^{(1)}$ and $\operatorname{IRT}_{m \times n}^{(0)}$, differential matrix $218 \Delta \operatorname{IRT}_{m \times n}^{(1)}$ is calculated. Eventually, with the aid of MATLAB, the differential 219 thermogram corresponding to $\Delta \mathrm{IRT}_{m \times n}^{(1)}$ is extracted. It should be noted that 220 differential thermograms had to be further rotated by $180 \mathrm{deg}$ around its vertical 221 central axis in order to match with the images captured by CCD camera. 
Confidential manuscript submitted to Journal of Geophysical Research: Solid Earth

222

223

224 shown at first. Given that the focus of present study is on the temperature response of

225 different types of cracks, only the infrared radiation characteristics of cracks in the

226 initiation and propagation processes were analyzed along with the strain fields.

\subsection{Cracking Behavior of Jointed Rock under Concentrated Load}

228 In order to investigate the cracking behavior under concentrated load, crack initiation,

229 propagation and coalescence processes of cracks beneath the left indenter are

230 examined using the strain fields computed from the CCD camera images.

231 Subsequently, on the basis of strain contours, crack types are determined.

232 Fracture processes of cracks beneath the left indenter are depicted in Figure 4. Figure

233 4a shows the initial state of rock specimen in the test. With increase in the

234 concentrated load, the normal and shear stresses also increase, resulting in shear

235 deformation of the joint plane. The joint shear deformation produced a small tensile

236 kink perpendicular to the joint plane in the region beneath the left indenter at $120 \mathrm{~s}$, as

237 illustrated in Figure 4b. Further loading, the kink propagated obliquely producing a

238 main crack which eventually propagated towards the indenter tip at $122 \mathrm{~s}$ (Figure 4c).

239 At the same time, indenter penetration resulted in the formation of tensile stresses at

240 the free surface at a distance from an indenter. When these tensile stresses equated to

241 the tensile strength of granite, a secondary crack (conical crack) is emanated from the 
Confidential manuscript submitted to Journal of Geophysical Research: Solid Earth

242 rock free surface and propagated towards the nearest joint plane. Two seconds later

243 (i.e. 124 s), secondary crack reached joint plane (Figure 4d).

244 Strain contours corresponding to Figure 4a, b and c are calculated by DIC technique,

245 as depicted in Figure 5. Contours of horizontal strain, vertical strain and shear strain

246 are included. The positive values of horizontal and vertical strains represent the

247 tensile strain while the negative values denote compressive strain. For horizontal

248 strain contours (Figure 5a), obvious tensile strain concentration zone could be

249 observed between the left indenter and joint plane when the main crack is initiated

250 (120 s). After that, tensile strain concentration area continued to propagate. At the

251 secondary crack region, horizontal strain along the crack trajectory is little larger than

252 other zone. However, in vertical strain field shown in Figure 5b, no obvious strain

253 concentration is observed at both the trajectories of main and secondary cracks. In

254 shear strain field (Figure 5c), zone of shear strain concentration only appears at the

255 location of main crack. While along the secondary crack, variation of shear strain is

256 not obvious in the cracking process. From the strain fields, it is concluded that the

257 main crack occurs due to the tensile and shear stress, while the secondary crack is

258 mainly caused by tensile stress. Therefore, patterns of main and secondary cracks are

259 the mixed shear-tensile and the tensile cracks, respectively.

260 To better illustrate the thermal effect of fracture process for different types of cracks,

261 main and secondary cracks depicted in Figure 4 will be respectively renamed as the

262 mixed shear-tensile and the tensile cracks in the sections below. 
Confidential manuscript submitted to Journal of Geophysical Research: Solid Earth

263

264

265

266

267 with different crack types. Consequently, on the basis of the evolutions of infrared

268 thermograms and IRT at initiation points of crack, the thermal features of crack

269 initiation are shown in this section.

270 During the experiment, the infrared thermograms of rock sample surface were

271 recorded in the fracture process. Differential thermograms at time of crack initiation

272 (120 s and $122 \mathrm{~s}$ ) are depicted in Figure. 6. Besides, to highlight the temperature

273 variations in local area, a term "temperature concentration factor (TCF)" is introduced,

274 which is given by

276 where $\Delta \mathrm{IRT}_{i, j, t}$ denotes the differential infrared radiation temperature of a point $(i, j)$

277 at the time $t, \Delta \mathrm{AIRT}_{t}$ represents the differential average infrared radiation

278 temperature of the whole rock surface at the time t. $\Delta \mathrm{IRT}_{i, j, t}$ and $\Delta \mathrm{AIRT}_{t}$ can be

279 obtained from differential thermograms. Larger TCF value indicates higher

280 temperature at the studied point compared with the average temperature on the whole

281 rock surface.

282 Figure 6 also depicts TCF at initiation points of the mixed shear-tensile crack (point 
Confidential manuscript submitted to Journal of Geophysical Research: Solid Earth

283 A ) and tensile crack (point B) as a function of time. For the mixed shear-tensile crack,

284 it is found that TCF increase gradually before $120 \mathrm{~s}$. Then the value rises dramatically

285 from 1.29 to 1.71 . Accordingly, highlighted temperature localization zone appears at

286 point A when $t=120 \mathrm{~s}$. However, the variation of TCF at initiation point of the tensile

287 crack shows a different trend. From 0 to $122 \mathrm{~s}$, TCF generally decrease from 1.50 to

288 1.14, but at the time of crack initiation (122 s), TCF reaches the minimum value of

289 1.00. At this time, no obvious temperature localization zone appears at the initiation

290 point for the tensile crack. In contrast, along the mixed shear-tensile crack, high

291 temperature zone extends to the free surface near the indenter region.

292 That is to say, the sudden appearance of high temperature zone extends could be seen

293 as the temperature characteristic of the mixed shear-tensile crack initiation. For the

294 tensile crack, however, the highlighted temperature zone is not obvious because the

295 temperature reaches the minimum value at the time of rupture.

2964 Discussion

297 The thermomechanical coupling effect is defined as the heat production in a solid due

298 to stress action. Therefore, thermal features of jointed rock layer under concentrated

299 load are closely related to the stress conditions. In this part, with the aim to reveal the

300 correlation between stress and IRT at jointed rock layer during the crack initiation,

301 and propagation processes, comparison between strain fields and differential

302 thermograms in the cracking process are made. Then, based on the thermomechanical 
Confidential manuscript submitted to Journal of Geophysical Research: Solid Earth

303 coupling effect, the mechanism of IRT characteristics at crack initiation points is

304 explained. In addition, new criteria for the crack propagation from thermal

305 perspective are proposed. Finally, thermal concentration effect at both crack initiation

306 and coalescence points are described.

4.1 Comparison Between Strain fields and Differential Thermograms during

$308 \quad$ Cracking Processes

309 During the infrared detection process, it is necessary to identify the hidden features in

310 layer on the basis of infrared fields. To investigate the relation between thermal

311 features of jointed layer at their failure region and corresponding cracking behaviors,

312 comparisons between differential thermograms and strain fields are made.

313 The evolutions of infrared radiation fields and corresponding strain fields in cracking

314 process are illustrated in Figures 6 and 5 respectively. For the mixed shear-tensile

315 crack, it is found that highlighted temperature localization zone extends from point A

316 to the zone beneath the left indenter in the crack initiation and propagation processes.

317 Correspondingly, tensile and shear strain concentrations appear along the trajectory of

318 the crack. However, for the tensile crack, no obvious high temperature zone appears

319 along the crack. From strain fields, it can be seen that tensile strain accumulation in

320 the tensile crack region is much larger than the shear strain.

321 By comparison, it is concluded that the shear deformation of crack plays a decisive

322 role in the highlighted temperature localization. This can be explained by the 
Confidential manuscript submitted to Journal of Geophysical Research: Solid Earth

323 frictional-thermal effect, which means the heat production caused by friction between

324 rock grains and micro friction of closed micro-cracks inside the rock. To investigate

325 the shear deformation mode of cracks, 5 evenly distributed points each along the

326 mixed shear-tensile crack and side tensile crack are selected, as shown in Figure 7.

327 These points are numbered from 1 to 10 in sequence. The variations of shear strain for

328 the mixed shear-tensile and tensile cracks are illustrated in Figure 8 (a) and (b),

329 respectively. By comparison, it is seen that shear strain along the mixed shear-tensile

330 crack increase gradually after $100 \mathrm{~s}$, indicating friction between rock grains and

331 between microcracks. After 120 s, shear strain increases dramatically followed by

332 macro-crack formation. More friction heat is produced, causing obvious temperature

333 concentration zone along the crack trajectory, whereas the shear strain in the tensile

334 crack region maintains stable during the whole experiment, therefore, the

335 frictional-thermal effect is not seen in the cracking process. This has some

336 implications in the geological prospecting. The shear deformation of strata is

337 commonly encountered (e.g., landslide, slope stability, fault movement in earthquakes

338 or reservoir induced seismicity). Locations of shear failure in strata can be found

339 according to the highlighted temperature localization zone in IRT fields.

$340 \quad 4.2$ Understanding of IRT Mechanism of Jointed Rock Layer Induced by $341 \quad$ Stress at Crack Initiation Points

$342 \mathrm{Wu}$ et al. (2006a) pointed out that the thermoelastic effect and the frictional-thermal 
Confidential manuscript submitted to Journal of Geophysical Research: Solid Earth

343 effect are two of the main mechanisms that affecting the IRT of loaded rock. Although

344 the IRT mechanism of rock has been investigated by many researches, thermal

345 features at crack initiation points are not captured properly. Therefore, in this study,

346 stress states of crack initiation points are firstly determined on the basis of strain fields.

347 Then, according to the thermoelastic effect and the frictional-thermal effect, the

348 influence of stress on IRT mechanism at the point of crack initiation in jointed rock

349 layers is explored.

350 Overall, the thermomechanical coupling effect is divided into thermoelastic, 351 thermoplastic and thermoviscous effects (Harwood and Cummings, 1991). Due to the

352 obvious brittleness and high compression strength of tested granite sample, the plastic

353 and viscous deformation of rock could be ignored ( $\mathrm{Wu}$ et al. 2006a). In addition,

354 study conducted by Chen et al. (2015) shows that pure shear deformation is a plastic

355 deformation, which could not produce any heat in the early stages of loading.

356 Therefore, only the thermoelastic effect is taken into consideration before the crack

357 initiation process. According to the thermoelastic effect, relationship between surface

358 physical temperature change and the stress is:

$$
\Delta T=-\frac{\alpha}{\rho C_{p}} T \Delta\left(\sigma_{1}+\sigma_{2}+\sigma_{3}\right)
$$

360 where $\Delta T$ is the change of temperature in $\mathrm{K}, T$ refers to absolute temperature of the

361 surface of the solid, in $\mathrm{K}, \alpha$ represents the factor of linear thermal expansion in $\mathrm{K}^{-1}, \rho$

362 stands for density of solid $\left(\mathrm{Kg} / \mathrm{m}^{3}\right), C_{p}$ denotes the heat capacity of solid at normal 
363 atmosphere $\left(\mathrm{J} \cdot \mathrm{kg}^{-1} \mathrm{~K}^{-1}\right), \Delta\left(\sigma_{1}+\sigma_{2}+\sigma_{3}\right)$ is the sum of principal stress in MPa. It

364 should be noted that $\sigma<0$ represents compressive stress. That is to say, the

365 temperature of the solid will be increased under the compression and it would be

366 reduced under the tension. Beside, in this experiment, jointed rock mass sample is

367 loaded under plane stress, thus $\sigma_{2}=0$.

368 In the plane stress problem, $\sigma_{1}$ and $\sigma_{3}$ are expressed as:

$$
\left.\begin{array}{l}
\sigma_{1} \\
\sigma_{3}
\end{array}\right\}=\frac{\sigma_{x}+\sigma_{y}}{2} \pm \sqrt{\left(\frac{\sigma_{x}+\sigma_{y}}{2}\right)^{2}+\tau_{x y}^{2}}
$$

370 Since principal stress coincide with $\mathrm{x}$ and $\mathrm{y}$ direction in the experimental set up, and

371 they can be related as:

$$
\sigma_{1}+\sigma_{3}=\sigma_{x}+\sigma_{y}
$$

373 By substituting Equation 4 into Equation 2, $\Delta T$ can be calculated

$$
\Delta T=-\frac{\alpha}{\rho C_{p}} \Delta\left(\sigma_{x}+\sigma_{y}\right)
$$

375 To explore the stress conditions of jointed rock, the horizontal, vertical and shear 376 strains (corresponding to $\varepsilon_{x}, \varepsilon_{y}$ and $\gamma$ ) at initiation points for the mixed 377 shear-tensile crack and tensile crack are calculated through the DIC technology, the 378 results are present in Figure 9. In this figure, negative and positive $\varepsilon_{x}$ or $\varepsilon_{y}$ 379 represent compression and tensile deformation, respectively. From Figure 9, it is 380 concluded that the stress state at initiation point for the mixed shear-tensile crack 381 changes from biaxial compression to the horizontal tension-vertical compression in 382 the elastic stage. In the crack initiation process, frictional sliding of the crack takes 
383 place. For the tensile crack, the stress state at initiation point changes from uniaxial 384 compression to uniaxial tension in the whole loading process, frictional sliding is not 385 obvious during the crack initiation.

386 According to stress states mentioned above, in the case of the mixed shear-tensile 387 crack, the thermoelastic effect is the main factor influencing the IRT of initiation point 388 just before the failure occurs. During the crack initiation process, the 389 frictional-thermal effect is more prominent. As for the tensile crack, the IRT is only 390 determined by the thermoelastic effect.

391 In elastic stress state, $\varepsilon_{x}$ and $\varepsilon_{y}$ are calculated using generalized Hooke's Law as 392 follows:

$$
\left\{\begin{array}{l}
\varepsilon_{x}=\frac{1}{E}\left(\sigma_{x}-\mu \sigma_{y}\right) \\
\varepsilon_{y}=\frac{1}{E}\left(\sigma_{y}-\mu \sigma_{x}\right)
\end{array}\right.
$$

394 where $E$ and $\mu$ are the Young's modulus and Poisson's ratio of rock, respectively. $\sigma_{x}$ 395 and $\sigma_{y}$ are horizontal and vertical stresses acting on the rock. Therefore, $\sigma_{x}$ and $396 \sigma_{y}$ is expressed as:

$$
\left\{\begin{array}{l}
\sigma_{x}=\frac{1}{1-\mu^{2}}\left(E \varepsilon_{x}+\mu E \varepsilon_{y}\right) \\
\sigma_{y}=\frac{1}{1-\mu^{2}}\left(E \varepsilon_{y}+\mu E \varepsilon_{x}\right)
\end{array}\right.
$$

398 According to $\varepsilon_{x}$ and $\varepsilon_{y}$ obtained from DIC technology, $\sigma_{x}$ and $\sigma_{y}$ can be 399 calculated using Equation (7). For the mixed shear-tensile crack, $\varepsilon_{y}$ is much larger 400 than $\varepsilon_{x}$ in the elastic stage. In addition, from equation (5), it is deduced that: 


$$
\Delta T=\Delta T_{x}+\Delta T_{y}=-\frac{\alpha}{\rho C_{p}} \Delta \sigma_{x}-\frac{\alpha}{\rho C_{p}} \Delta \sigma_{y}
$$

$$
\frac{\Delta T_{x}}{\Delta T_{y}}=\frac{\Delta \sigma_{x}}{\Delta \sigma_{y}}
$$

$\sigma_{x}$ and $\sigma_{y}$ obtained from DIC technology (Eq. 7) are equal to $\Delta \sigma_{x}$ and $\Delta \sigma_{y}$,

404 respectively. By substituting equation (7) into equation (9), the proportions of

405 temperature caused by horizontal and vertical stresses are obtained. The temperature

406 proportion for the mixed shear-tensile crack is shown in Figure 10. From this figure, it

407 can be observed that the proportion of $\Delta T_{y}$ continues to increase with time. But at

408 the time before crack initiation, horizontal strain becomes positive, causing the

409 reduction in temperature. Thus the proportion of $\Delta T_{x}$ is defined as positive. Whereas,

410 the proportion of $\Delta T_{y}$ at that corresponding time becomes numerically larger than

$411100 \%$. That is to say, $\sigma_{y}$ play a decisive role in heat production for the mixed

412 shear-tensile crack before the crack initiation. Vertical stress acting on the initiation

413 point of this crack increases continually (Figure 9b), causing the increase in the

414 temperature. As a result, TCF of the mixed shear-tensile crack increases gradually

415 before the failure. At the time just before the crack initiation, dramatic increase in $\gamma$

416 indicates the obvious frictional-thermal effect, leading to the sudden increase in TCF

417 and highlighted temperature zone on the rock surface. As for the tensile crack is

418 concerned, the IRT is only determined by the thermoelastic effect. Generally, the

419 horizontal stress acting on the initiation point varies from compression to tension, the

420 change of sum of principal stress is positive, causing the continue decrease in TCF, as 
Confidential manuscript submitted to Journal of Geophysical Research: Solid Earth

421 shown in Figure 6.

422 From the characteristics of TCF, the failure zone of jointed rock with different crack

423 types can be detected once the cracks initiate, especially the mixed shear-tensile crack

424 and shear crack. This phenomenon is found similar to that of results of Liu et al.

425 (2006), in which a uniaxial compression test and the compressively induced shearing

426 test were conducted on rock samples. At failure moment, it was found that both the

427 shear fractures were accompanied by highlighted IRT concentration. The main

428 reasons are attributed to the frictional-thermal effect.

4.3 Crack Propagation Criteria based on Thermal Effects

430 In fracture mechanics, several criterions for crack propagation have been proposed

431 from the perspective of stress and energy, such as the maximum circumferential stress

432 criterion, the energy release rate criterion and the strain energy density criterion.

433 However, from thermal point of view, the crack propagation criteria have been

434 scarcely studied. In this section, the maximum temperature gradient criterion and the

435 minimum temperature gradient criterion are firstly proposed according to IRT results.

436 Based on these criteria, the direction of crack propagation can be determined.

437 To compare IRT at zones nearby the crack tips with that at point $1-10,8$ circles or

438 semicircles which numbered I, II, III, IV, VI, VII, VIII and IX were selected, the

439 corresponding centers of them are point $1,2,3,4,6,7,8$ and 9 , respectively (Figure

440 7). Radii of circles or semicircles are equal to the distance between the adjacent points 
Confidential manuscript submitted to Journal of Geophysical Research: Solid Earth

441 on crack trajectories. Therefore, variations of differential temperature $\Delta$ IRT at these

442 points with time, before crack coalescence, were calculated. After that, the term

443 "temperature gradient" is proposed. It reflects the change in temperature over the

444 circle or semicircle, which is obtained by

$$
G_{T i}=\frac{\Delta \mathrm{IRT}_{i+1}-\Delta \mathrm{IRT}_{i}}{r_{i}} \quad(i=1,2,3,4,6,7,8,9)
$$

446 Where $G_{T i}$ is the temperature gradient at zones around point $i, \Delta \mathrm{IRT}_{i}$ and $\Delta \mathrm{IRT}_{i+1}$

447 represent the differential temperature at $i$ th point and $(i+1)$ th point on circle or

448 semicircle, respectively. $r_{i}$ is radius of $i$ th circle or semicircle.

449 From Equation 10, the temperature gradient at any time is calculated. Subsequently, 450 average temperature gradients from $0 \mathrm{~s}$ to the time just before crack coalescence are

451 obtained, as illustrated in Figure 11. Obviously, for each circle or semicircle along the 452 shear-tensile crack, the average temperature gradient at the time of failure is larger 453 than others points. On the contrary, in the case of the tensile crack, the average 454 temperature gradient at the time of failure is the minimum. In another word, the mixed 455 shear-tensile crack propagates toward the direction where the average temperature 456 gradient is maximum, while the tensile crack propagates toward the direction where 457 the average temperature gradient is minimum, and these are termed as "the maximum 458 temperature gradient criterion" and "the minimum temperature gradient criterion", 459 respectively.

460 The criteria can be explained by the thermoelastic effect and the frictional-thermal 
461 effect. As mentioned in section 4.2, before the crack initiation, the thermoelastic effect

462 is considered as the main mechanism of heat production. From Equation 5, it can be

463 deduced that the change in IRT is a linear function of $\sigma_{x}+\sigma_{y}$. Similarly, "stress

464 gradient" around the crack tip is defined as below:

$$
G_{S i}=\frac{\left(\sigma_{x}+\sigma_{y}\right)_{i+1}-\left(\sigma_{x}+\sigma_{y}\right)_{i}}{r_{i}} \quad(i=1,2,3,4,6,7,8,9)
$$

466 Where $G_{S i}$ represents the stress gradient at zones around point $i,\left(\sigma_{x}+\sigma_{y}\right)_{i}$ and $467\left(\sigma_{x}+\sigma_{y}\right)_{i+1}$ are the sum of horizontal and vertical stress at $i$ th point and $(i+1)$ th point 468 (i.e., circle or semicircle), respectively. Similarly, average stress gradients from $0 \mathrm{~s}$ to 469 the time just before crack coalescence are calculated, as shown in Figure 11. For 470 points at the same circles or semicircles, strong correlation between temperature 471 gradient and stress gradient along the cracks can be found. Especially, the average 472 stress gradients at the mixed shear-tensile is smaller than that of at other points, while 473 the values at tensile cracks are larger than other points. This phenomenon indicates 474 that the compressive stress dominates the trajectory of the mixed shear-tensile crack, 475 negative stress gradient stands for the increase in compression. As a result, 476 temperature along the shear-tensile crack is larger than other zone. In the crack 477 propagation process, frictional-thermal effect also leads to the increase in temperature. 478 Subsequently, heating zone occurs along the shear-tensile crack. However, for the 479 tensile crack, positive stress gradient represents the increase in tensile, causing 480 reduction in temperature in that zone. Temperature fields along the cracks are 
Confidential manuscript submitted to Journal of Geophysical Research: Solid Earth

481 illustrated in Figure 12. Consequently, compared with IRT with other zone, the 482 temperature gradients along the mixed shear-tensile crack is the maximum, while the 483 value along the tensile crack trajectory is the minimum.

485 In the present study, a new phenomenon is observed that the cracks show various 486 temperature concentration characteristics during the crack initiation, propagation and 487 coalescence processes. To investigate the thermal features in cracking processes, 488 temperature concentration factors (TCFs) of each point along the cracks (points 1-10 489 in Figure 7) are calculated. Regrettably, the trends of TCFs for each point cannot be 490 distinguished directly. Therefore, variances of TCFs from $0 \mathrm{~s}$ to the rupture time are 491 further calculated, results are shown in Figure 13a.

492 In Figure 13a, it is found that the variance trends of TCFs for the mixed shear-tensile 493 and tensile cracks are similar with each other. For each crack, variances of TCFs at 494 crack initiation point (i.e. point 1 or 6 ) and crack coalescence point (i.e. point 5 or 10) 495 are obviously more than that at other points. The phenomenon indicates that the 496 temperature change during crack initiation and coalescence processes is more 497 pronounced than that in crack propagation process.

498 To explain the temperature concentration effects during the different cracking stages,

499 the variances of $\Delta\left(\sigma_{x}+\sigma_{y}\right)$ for the corresponding points are calculated, and the 500 results are illustrated in Figure 13b. By comparison, it is seen that the variances of 
Confidential manuscript submitted to Journal of Geophysical Research: Solid Earth

501 TCF and $\Delta\left(\sigma_{x}+\sigma_{y}\right)$ have similar trends. Study done by Ma et al. (2018) also found

502 that the sudden changes in successive minus infrared image temperature often

503 accompanied with sudden changes in stress. Before the crack initiation, no obvious

504 flaws appear at the initiation points, so more stress is needed to achieve stress

505 concentration at the initiation points as $\Delta$ IRT is proportional to $\Delta\left(\sigma_{x}+\sigma_{y}\right)$. In

506 addition, from Figure 8, it is also found that obvious shear deformation takes place for

507 the mixed shear-tensile crack at the time of crack initiation. As a result, dramatic

508 change in IRT occurs during crack initiation stage. After that, cracks propagate stably,

509 causing the reduction in the variation of $\Delta\left(\sigma_{x}+\sigma_{y}\right)$. At the time of crack

510 coalescence, the mechanisms of stress change for the mixed shear-tensile and tensile

511 cracks differ. Overall, for the mixed shear-tensile crack, when the crack passes

512 through the rock, stress at crack tip disappears suddenly, causing the dramatic

513 decrease in IRT. However, for the tensile crack, when crack coalesces with the jointed

514 plane, concentrated stress at the crack tip overlay the stress along the jointed plane,

515 leading to the sudden increase in stress at crack coalescence point. The dramatic

516 change in IRT at crack initiation and coalescence points will be favorable for

517 determining the failure zone in jointed rock layers.

\section{Conclusions}

519 In the present study performs a series of indention tests on the jointed rock specimens

520 were performed to understand the fracture process of jointed layer under concentrated 
Confidential manuscript submitted to Journal of Geophysical Research: Solid Earth

521 load based on thermal characteristics and strain field characteristics. Thermal effects

522 in crack initiation, propagation and coalescence processes were investigated. Based on

523 the experimental results, some new understandings of infrared radiation features of

524 cracking processes in jointed rock mass are concluded as follows:

525 1. Comparisons between the strain fields and differential thermograms in cracking

526 processes indicate that the highlighted temperature localization in IRT fields mainly

527 caused by the frictional-thermal effect, while the effects of tensile and compressive

528 stresses are not quite conspicuous.

529 2. Based on the stress states obtained from DIC technique, ITR mechanisms at crack

530 initiation crack were highlighted. For the mixed shear-tensile crack, thermoelastic

531 effect and the frictional-thermal effect were dominant and they influence the IRT

532 distribution at the time of crack initiation and propagation. Whereas in case of tensile

533 crack, the IRT is only determined by the thermoelastic effect in cracking process.

534 3. The mixed shear-tensile crack and tensile crack propagate following the maximum

535 temperature gradient criterion and the minimum temperature gradient criterion,

536 respectively. The new thermal criteria are in congruent with that of the stress gradient

537 along the crack trajectories.

538 4. High variations in the IRT at crack initiation points and coalescence points are

539 observed than at other regions. Further, a strong correlation between the stress

540 gradient and the temperature gradient during the crack initiation and coalescence

541 process is observed. 
Confidential manuscript submitted to Journal of Geophysical Research: Solid Earth

\section{Acknowledgements}

543 The financial support from Project supported by graduate research and innovation

544 foundation of Chongqing, China (Grant No.CYB19015), Natural Science Fund of

545 China (Nos. 51879016) and the National Key R\&D Program of China, 546 No.2018YFC1505504) are greatly appreciated. Data supporting this research are 547 available in: https://data.mendeley.com/datasets/wy92dfnyds/draft?a=b1f355c9-7765 $548-462 \mathrm{c}-86 \mathrm{f} 2-77 \mathrm{~b} 4 \mathrm{ed} 4 \mathrm{bb} 574$. The authors declare no conflict of interest. No financial 549 and personal relationships with other people or organizations that can inappropriately 550 influence our work.

\section{References}

552 Alehoseein, H., Detournay, E., \& Huang, H. (2000), An analytical model for the indentation of 553 rocks by blunt tools. Rock Mechanics and Rock Engineering, 33(4), 267-284. 554 doi:10.1007/s006030070003

555 Bosea, N., \& Mukherjee, S. (2020), Estimation of deformation temperatures, flow stresses and 556 strain rates from an intra-continental shear zone: The Main Boundary Thrust, NW Himalaya 557 (Uttarakhand, India). Marine and Petroleum Geology, 112, 104094. doi:10.1016/j.marpetgeo. $558 \quad 2019.104094$

559 Chen, S., Liu, P., Guo, Y., Liu, L., \& Ma, J. (2015), An experiment on temperature variations in 560 sandstone during biaxial loading. Physics and Chemistry of the Earth, 85-86, 3-8. doi:10. 
Confidential manuscript submitted to Journal of Geophysical Research: Solid Earth

562 Chen, S., Liu, P., Liu, L., \& Ma, J. (2013), A phenomenon of ground temperature change prior to

563 Lushan earthquake observed in Kangding. Seismolog and Geology, 35(3), 634-640.

564 doi:10.3969/j.issn.0253-4967

565 Chen, S., Liu, P., Liu, L., \& Ma, J. (2016), Bedrock temperature as a potential method for

566 monitoring change in crustal stress: Theory, in situ measurement, and a case history. Journal

567 of Asian Earth Sciences, 123, 22-33. doi:10.1016/j.jseaes.2016.03.018

568 Cheng, C., Li, Z., Li, G., Wei, Y., Yin, S., Liu, S., \& Kong, Y. (2018), Influence of prefabricated

569 fissure angle on sandstone damage and infrared radiation temperature characteristics. Journal

570 of Geophysics and Engineering, 15(4), 1187-1196. doi:10.1088/1742-2140/aaacaf

571 Graham, C. M. \& England, P. C. (1976), Thermal regimes and regional metamorphism in the

572 vicinity of overthrust faults: An example of shear heating and inverted metamorphic zonation

573 from southern California. Earth and Planetary Science Letters, 31(1), 142-152. doi:10.1016/

$574 \quad 0012-821 X(76) 90105-9$

575 Harwood, N., \& Cummings, W. M. (1991), Thermoelastic stress analysis. Bristol: IOP Publishing

$576 \quad$ Ltd.

577 Johnson, K. L. (1985), Contact mechanics. Cambridge: Cambridge University Press.

578 Karekal, S. (2000), Analytical and experimental investigations of rock indentation process. In 9th

579 Annual JKMRC Conference, pp. 107-138.

580 Li, H., Xue, L., Brodsky, E. E., Mori, J. J., Fulton, P. M., Wang, H., Kano, K., Yun, K., Harris, R.

581 N., Gong, Z., Li, C., Si, J., Sun, Z., Pei, J., Zheng, Y., \& Xu, Z. (2015), Long-term

582 temperature records following the Mw 7.9 Wenchuan (China) earthquake are consistent with 
Confidential manuscript submitted to Journal of Geophysical Research: Solid Earth

583

584

585

586

587

588

589

590

591

592

593

594

595

596

597

598

599

600

601

602

603

low friction. Geology, 43(2), 163-166. doi:10.1130/g35515.1

Li, Z., Lou, Q., Wang, E., Liu, S., \& Niu, Y. (2017), Study on acoustic-electric-heat effect of coal and rock failure processes under uniaxial compression. Journal of Geophysics and Engineering, 15(1), 71-80. doi:10.1088/1742-2140/aa8437

Li, Z., Yin, S. \& Niu, Y. (2018), Experimental study on the infrared thermal imaging of a coal fracture under the coupled effects of stress and gas. Journal of natural gas science and engineering, 55, 444-451. doi:10.1016/j.jngse.2018.05.019

Liu, Q., Liu, Q., Pan, Y., Peng, X., Deng, P., \& Huang, K. (2018), Experimental study on rock indentation using infrared thermography and acoustic emission techniques. Journal of Geophysics and Engineering, 15, 1864-1877. doi:10.1088/1742-2140/aac096

Liu, S., Wu, L., \& Wu, Y. (2006). Infrared radiation of rock at failure. International Journal of Rock Mechanics \& Mining Sciences, 43, 972-979. https://doi.org/10.1016/j.ijrmms.2005.12.

009

Long, S., McQuarrie, N., Tobgay, T., \& Hawthorne, J. (2011), Quantifying internal strain and deformation temperature in the eastern Himalaya, Bhutan: implications for the evolution of strain in thrust sheets. Journal of Structural Geology, 33, 579-608. doi:10.1016/j.jsg.2010.12. 011

Lu, X., Meng, Q., Gu, X., Zhang, X., Xie, T., \& Geng, F. (2016), Thermal infrared anomalies associated with multi-year earthquakes in the Tibet region based on China's FY-2E satellite data. Advances in Space Research, 58(6), 989-1001. doi:10.1016/j.asr.2016.05.038

Ma, L., \& Sun, H. (2018), Spatial-temporal infrared radiation precursors of coal failure under 
Confidential manuscript submitted to Journal of Geophysical Research: Solid Earth

604 uniaxial compressive loading. Infrared Physics \& Technology, 93, 144-153. doi:10.1016/j.

$605 \quad$ infrared.2018.07.034

606 Ma, L., Sun, H., Zhang, Y., Hu, H., \& Zgang, C. G. (2018), The role of stress in controlling

607 infrared radiation during coal and rock failures. Strain, 54, e12295. doi:10.1111/str.12295

608 Milne, J. (1886), Earthquakes and Other Earth Movements. New York: D. Appleton and Co.

609 Mukherjee, S. (2017), Shear heating by translational brittle reverse faulting along a single, sharp

610 and straight fault plane. Journal of Earth System Science, 126, 1-5. doi:10.1007/s12040-016-

$611 \quad 0788-5$

612 Mulchrone, K. F., \& Mukherjee, S. (2016), Kinematics and shear heat pattern of ductile simple

613 shear zones with 'slip boundary condition'. International Journal of Earth Sciences, 105(3),

614 1015-1020. doi:10.1007/s00531-015-1206-y

615 Munoz, H., Taheri, A., \& Chanda, E. K. (2016), Pre-peak and post-peak rock strain characteristics

616 during uniaxial compression by 3D digital image correlation. Rock Mechanics and Rock

617 Engineering, 49(7), 2541-2554. doi:10.1007/s00603-016-0935-y

618 Ramasamy, S. M., Gunasekaran, S., Rajagopal, N., Saravanavel, J. \& Kumanan, C. J. (2019),

619 Flood 2018 and the status of reservoir-induced seismicity in Kerala, India. Natural Hazards,

620 99(1), 307-319. doi:10.1007/s11069-019-03741-x

621 Sanderson, D. J. (1982), Models of strain variation in nappes and thrust sheets: A review.

622 Tectonophysics, 88(3-4), 201-233. doi:10.1016/0040-1951(82)90237-2

623 Stiros, S. C. \& Pytharouli, S. (2018), Interpretations of reservoir-induced seismicity may not

624 always be valid: The case of seismicity during the impoundment of the Kremasta Dam 
Confidential manuscript submitted to Journal of Geophysical Research: Solid Earth

625

626

627

628

629

630

631

632

633

634

635

636

637

638

639

640

641

642

643

644

645

(Greece, 1965-1966). Bulletin of the Seismological Society of America, 108(5B), 3005-3015. doi:10.1785/0120170359

Sun, H., Ma, L., Adeleke, N., \& Zhang, Y. (2017), Background thermal noise correction methodology for average infrared radiation temperature of coal under uniaxial loading. Infrared Physics and Technology, 81, 157-165. doi:10.1016/j.infrared.2017.01.001

Sutton, M. A., Orteu, J. J., \& Schreier, H. (2009), Image correlation for shape, motion and deformation measurements. Berlin: Springer.

Tramutoli, V., Aliano, C., Corrado, R., Filizzola, C., Genzano, N., Lisi, M., Martinelli, G. \& Pergola, N. (2013), On the possible origin of thermal infrared radiation (TIR) anomalies in earthquake-prone areas observed using robust satellite techniques (RST). Chemical Geology, 339, 157-168. doi:10.1016/j.chemgeo.2012.10.042

Wu, L., Liu, S., Wu, Y. \& Wang, C. (2006a), Precursors for rock fracturing and failure-Part I: IRR image abnormalities, International Journal of Rock Mechanics \& Mining Sciences, 43, 473-482. doi:10.1016/j.ijrmms.2005.09.001

Wu, L., Liu, S., Wu, Y., \& Wang, C. (2006b), Precursors for rock fracturing and failure-Part II: IRR T-Curve abnormalities. International Journal of Rock Mechanics \& Mining Sciences, 43, 483-493. doi:10.1016/j.ijrmms.2005.09.001

Xiong, P., Shen, X., Gu, X., Meng, Q.,Bi, Y., Zhao, L., Zhao, Y., Li, Y., \& Dong, J. (2015), Satellite detection of IR precursors using bi-angular advanced along-track scanning radiometer data: a case study of Yushu earthquake. Earthquake Science, 28(1), 25-36. doi:10.1007/s11589-015-0111-6 
Confidential manuscript submitted to Journal of Geophysical Research: Solid Earth

646 Yang, H., Li, Z., Jie, T., \& Zhang, Z. (2018a), Effects of joints on the cutting behavior of disc

647 cutter running on the jointed rock mass. Tunnelling and Underground Space Technology, 81,

$648 \quad$ 112-120. doi:10.1016/j.tust.2018.07.023

649 Yang, H., Liu, J., \& Liu, B. (2018b), Investigation on the cracking character of jointed rock mass

650 beneath TBM disc cutter. Rock Mechanics and Rock Engineering, 51, 1263-1277.

651 doi:10.1007/s00603-017-1395-8

652 Zhao, Y., Yang, H., Chen, Z., Chen, X., Huang, L., \& Liu, S. (2019), Effects of jointed rock mass

653 and mixed ground conditions on the cutting efficiency and cutter wear of tunnel boring

654 machine. Rock Mechanics and Rock Engineering, 52, 1303-1313.

655 doi:10.1007/s00603-018-1667-y 


\section{Headings}

6571 Introduction

6582 Experimental Methodology

$659 \quad 2.1$ Preparation for Specimen and Rock Properties

$660 \quad 2.2$ Test Apparatus

$661 \quad 2.3$ Experimental Process

$662 \quad 2.4$ Data Analysis

6633 Results

664 3.1 Cracking Behavior of Jointed Rock under Concentrated Load

665 3.2 Thermal Features during the Initiation of Mixed Shear-tensile Crack and Tensile

666 Crack

6674 Discussion

668 4.1 Comparison Between Strain fields and Differential Thermograms during Cracking

669 Processes

6704.2 Understanding of IRT Mechanism of Jointed Rock Layer Induced by Stress at

671 Crack Initiation Points

672 4.3 Crack Propagation Criteria based on Thermal Effects

6734.4 Temperature Concentration Effects during the Different Cracking Stages

6745 Conclusions

675 
Confidential manuscript submitted to Journal of Geophysical Research: Solid Earth

676 Figure or Table Captions

677 Figure 1. The picture of jointed rock mass sample (unit: $\mathrm{mm}$ ).

678 Figure 2. Test system and experimental setup. (a) The positions of indenters and

679 jointed rock specimen, (b) experimental system, (c) the back of rock specimen, (d) the

680 front of rock specimen.

681 Figure 3. Schematic diagram of the methodology for calculating differential infrared

682 thermograms. Step 1: Extraction of IRT matrix of the whole image by IRT software.

683 Step 2: Extraction of IRT matrix at the rock mass zone. Step 3: Calculation of the

684 differential temperature. Step 4: Extracting the differential thermograms.

685 Figure 4. Cracking process of jointed rock under local stress at . (a) 0s; (b) $120 \mathrm{~s}$; (c)

$686122 \mathrm{~s} ;$ (d) $124 \mathrm{~s}$.

687 Figure 5. The evolution of strain fields of jointed rock during the cracking. (a) The

688 horizontal strain. (b) Vertical strain. (c) Shear strain.

689 Figure 6. Curves of temperature concentration factors of initiation points for the

690 mixed shear-tensile and tensile cracks. The corresponding differential thermograms of

691 jointed rock mass at the time of crack initiation are depicted. Initiation points for the

692 mixed shear-tensile and tensile cracks are point A and point B, respectively.

693 Figure 7. The positions for data collection at the mixed shear-tensile crack and tensile

694 crack.

695 Figure 8. Variations of shear strain along (a) the mixed shear-tensile crack and (b) 
696 tensile crack.

697 Figure 9. The variations of (a) horizontal strain, (b) vertical strain and (c) shear strain

698 of mixed shear-tensile crack and tensile crack in cracking process.

699 Figure 10. The proportion of temperature caused by $\sigma_{x}$ and $\sigma_{y}$ at initiation points for

700 the mixed shear-tensile crack.

701 Figure 11. Comparisons between average temperature gradients and stress gradients

702 along the cracks, (a) the mixed shear-tensile crack, (b) tensile crack.

703 Figure 12. Temperature field along the cracks. Healing zone and cooling zone occur

704 along the trajectories of the mixed shear-tensile crack and tensile crack, respectively.

705 Figure 13. Comparisons between (a) variances of temperature concentration factor

706 and (b) $\left(\sigma_{x}+\sigma_{y}\right)$ for the mixed shear-tensile crack and tensile crack.

707 Table 1. Physical and mechanical properties of granite and jointed plane.

708

709

710

711

712

713

714

715

716 


\section{Confidential manuscript submitted to Journal of Geophysical Research: Solid Earth}

\section{8}

719

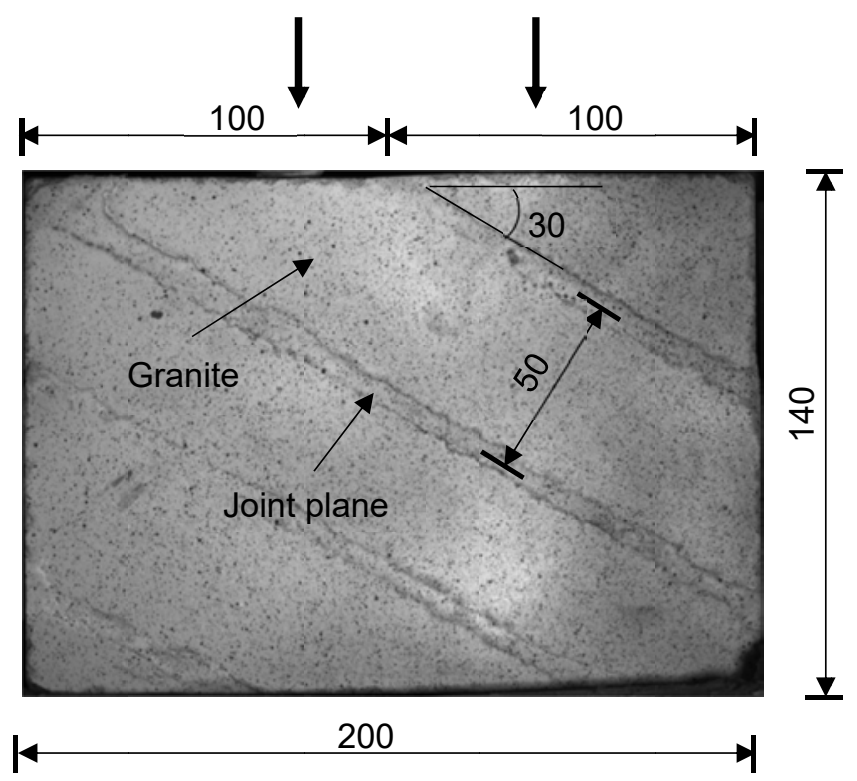

Figure 1. The picture of jointed rock mass sample (unit: $\mathrm{mm}$ ). 
Confidential manuscript submitted to Journal of Geophysical Research: Solid Earth
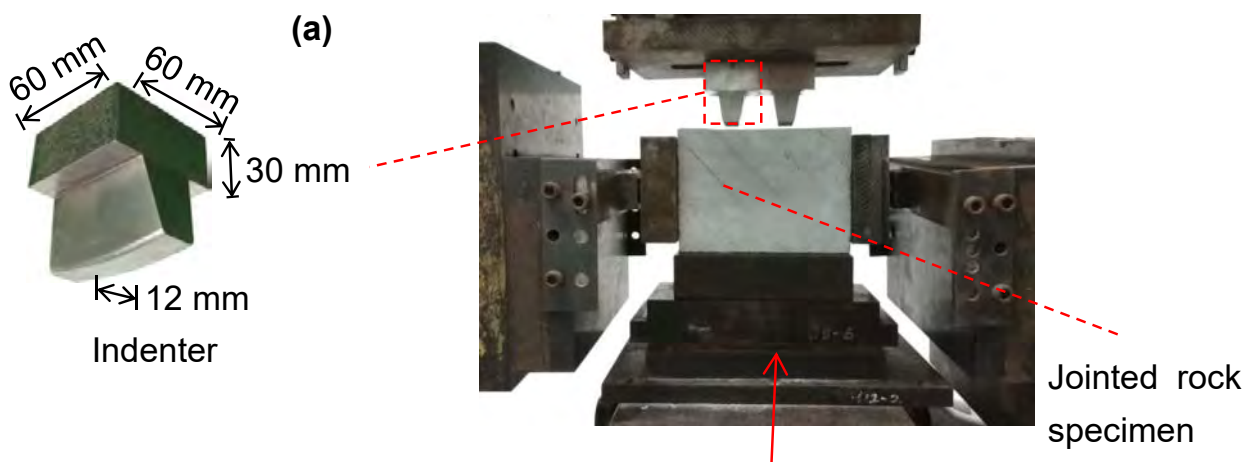

(b)

Control system

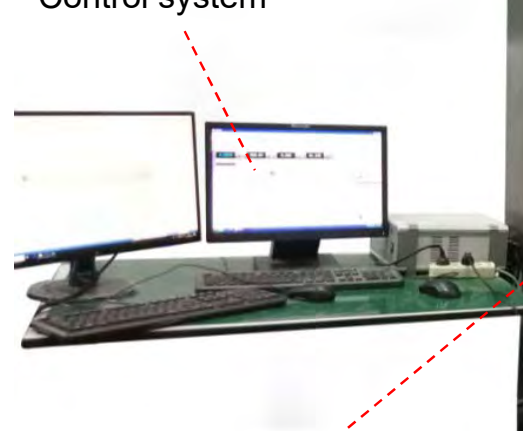

MTS servo-hydraulic machine

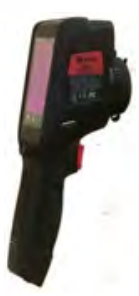

D384M infrared camera

(c)
723 Figure 2. Test system and experimental setup. (a) The positions of indenters and

724 jointed rock specimen, (b) experimental system, (c) the back of rock specimen, (d) the 725 front of rock specimen. 


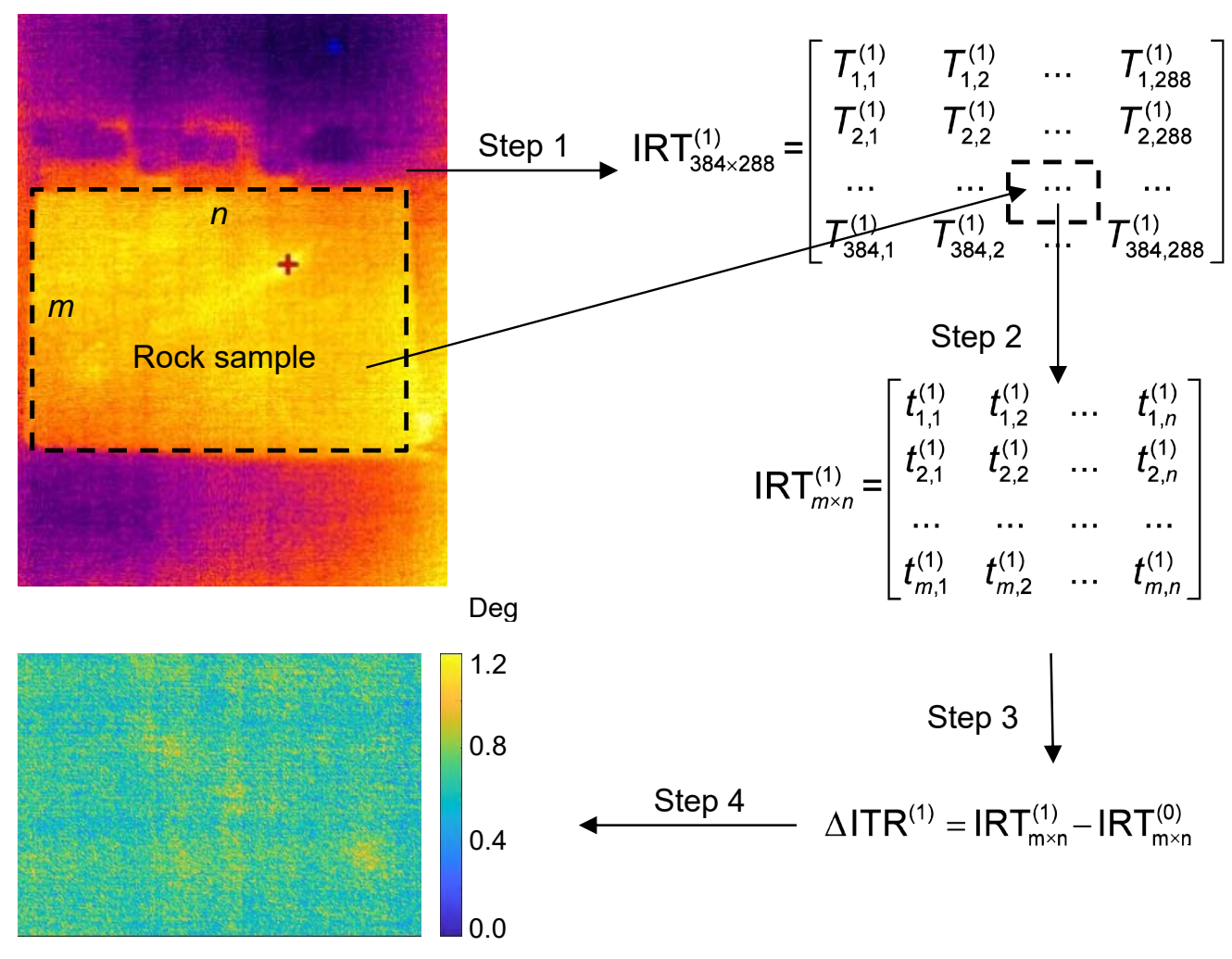

727 Figure 3. Schematic diagram of the methodology for calculating differential infrared

728 thermograms. Step 1: Extraction of IRT matrix of the whole image by IRT software.

729 Step 2: Extraction of IRT matrix at the rock mass zone. Step 3: Calculation of the

730 differential temperature. Step 4: Extracting the differential thermograms. 


\section{Confidential manuscript submitted to Journal of Geophysical Research: Solid Earth}
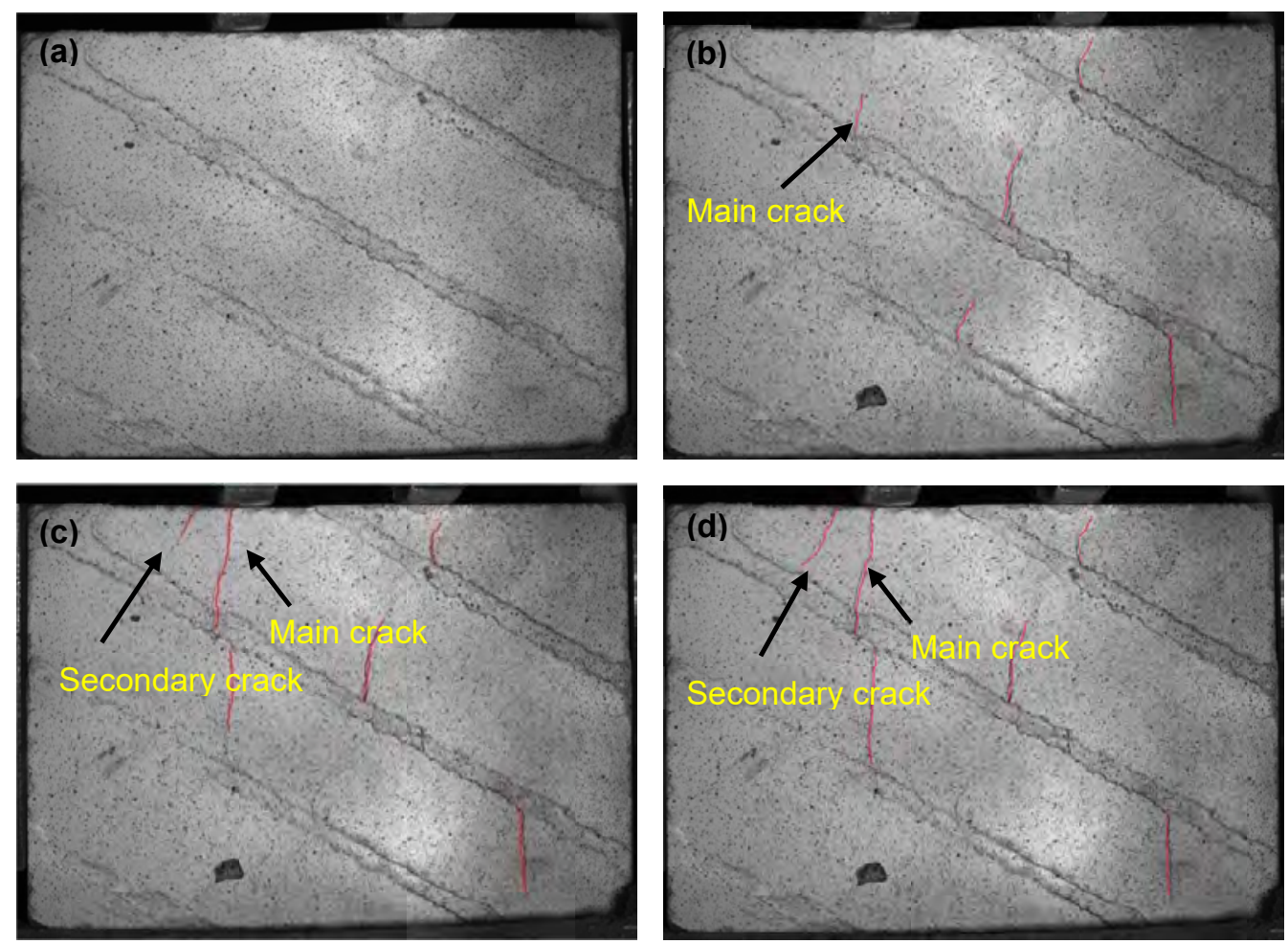

734 Figure 4. Cracking process of jointed rock under local stress at . (a) 0s; (b) $120 \mathrm{~s}$; (c)

$735122 \mathrm{~s} ;(\mathbf{d}) 124 \mathrm{~s}$. 
(a) $\varepsilon_{\mathrm{x}} \quad 120 \mathrm{~s}$
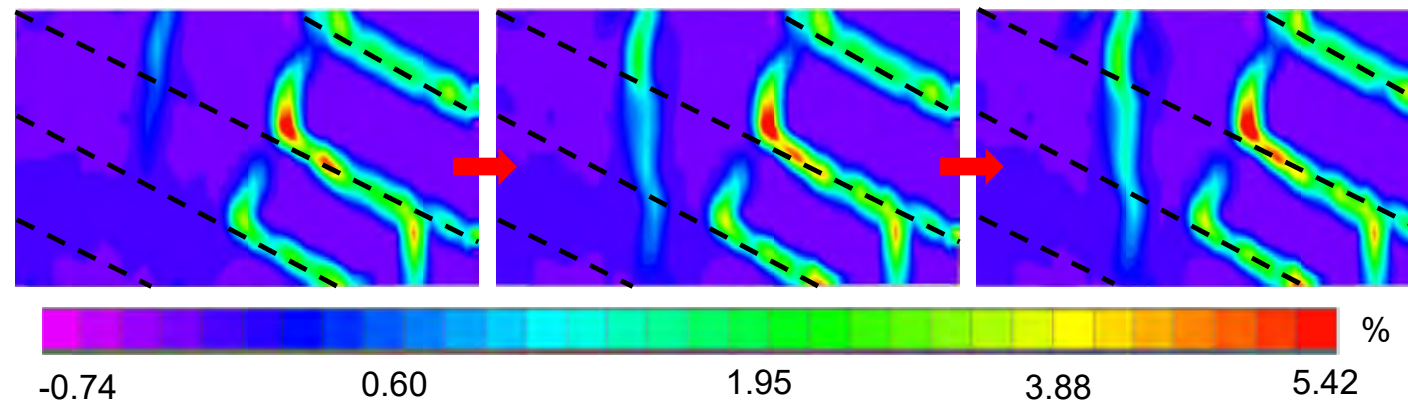

(b) $\varepsilon_{\mathrm{y}} \quad 120 \mathrm{~s}$

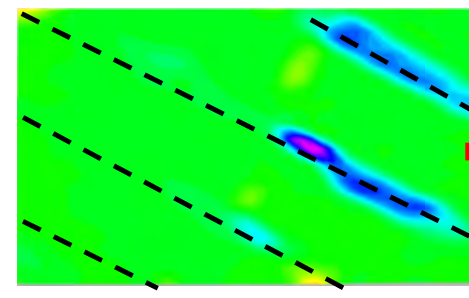

$122 \mathrm{~s}$
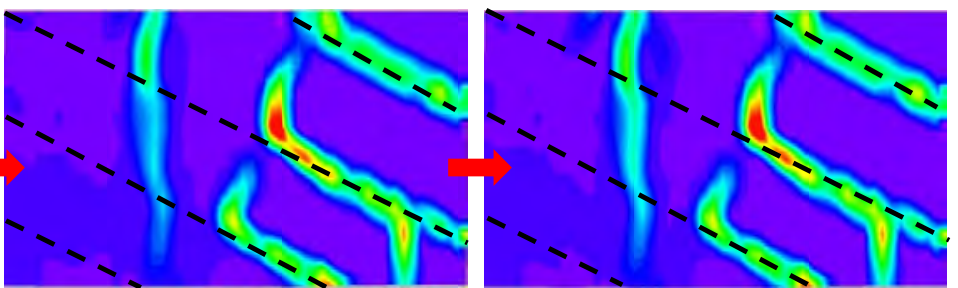

3.88

$124 \mathrm{~s}$

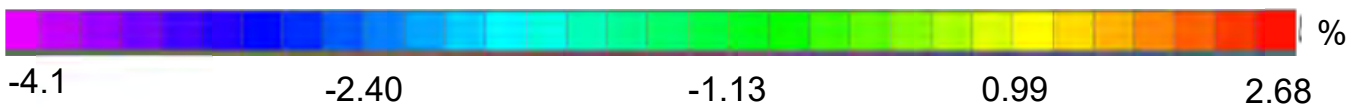

(c) $\gamma 120 \mathrm{~s}$

$122 \mathrm{~s}$

$124 \mathrm{~s}$

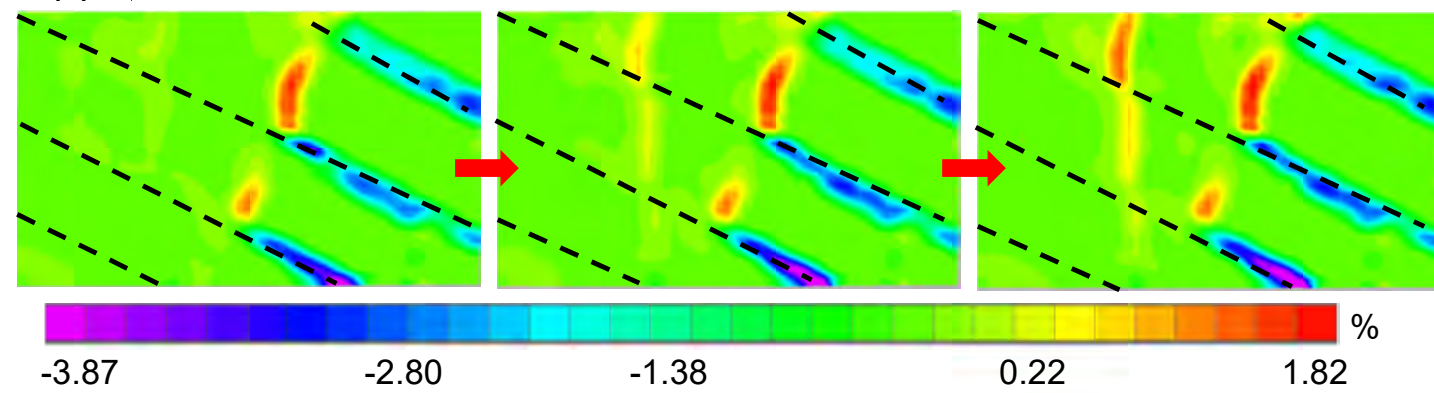

735

Figure 5. The evolution of strain fields of jointed rock during the cracking. (a) The

738 horizontal strain. (b) Vertical strain. (c) Shear strain. 
Confidential manuscript submitted to Journal of Geophysical Research: Solid Earth

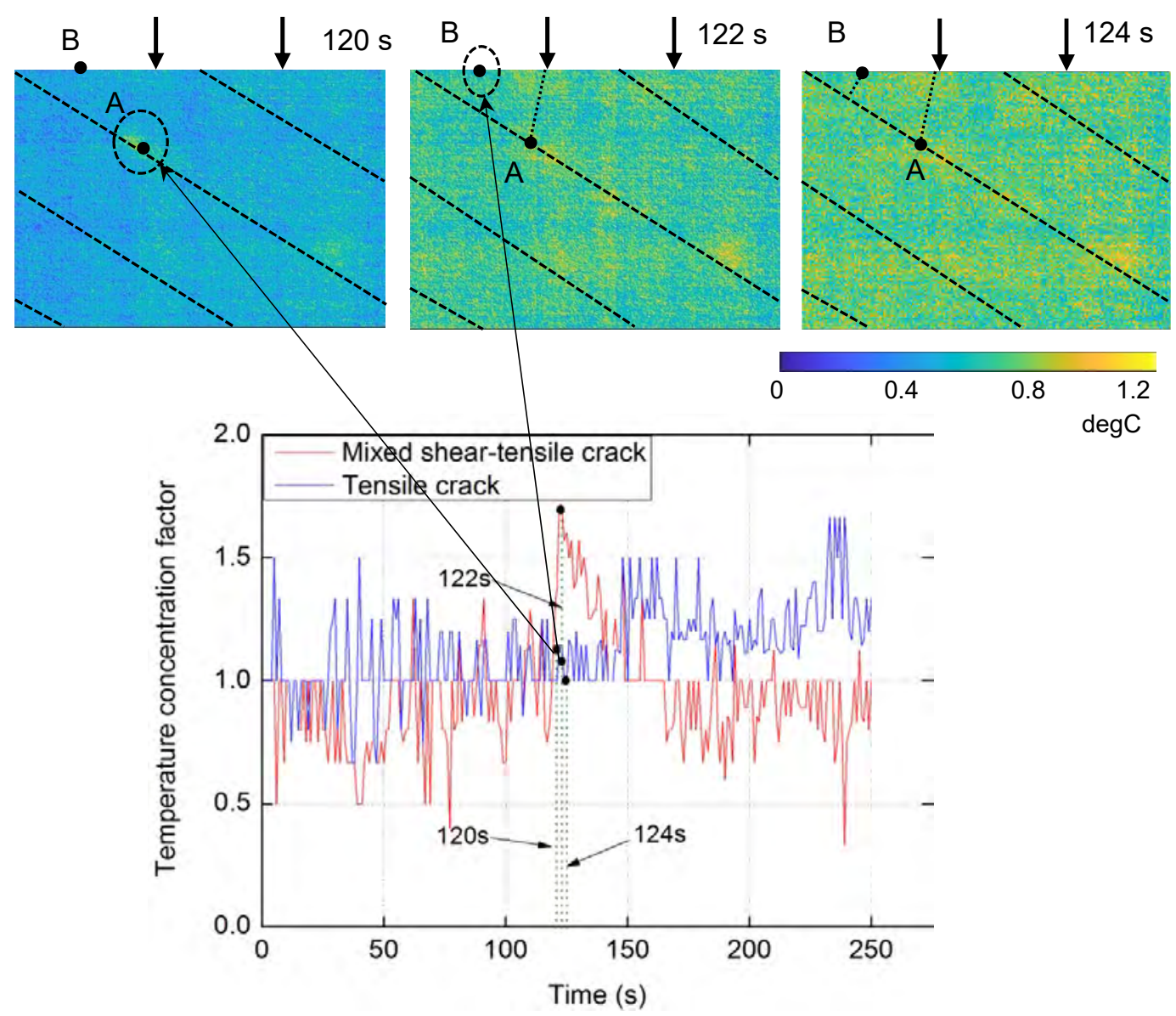

738 Figure 6. Curves of temperature concentration factors of initiation points for the

739 mixed shear-tensile and tensile cracks. The corresponding differential thermograms of

740 jointed rock mass at the time of crack initiation are depicted. Initiation points for the

741 mixed shear-tensile and tensile cracks are point A and point B, respectively. 
Confidential manuscript submitted to Journal of Geophysical Research: Solid Earth

743

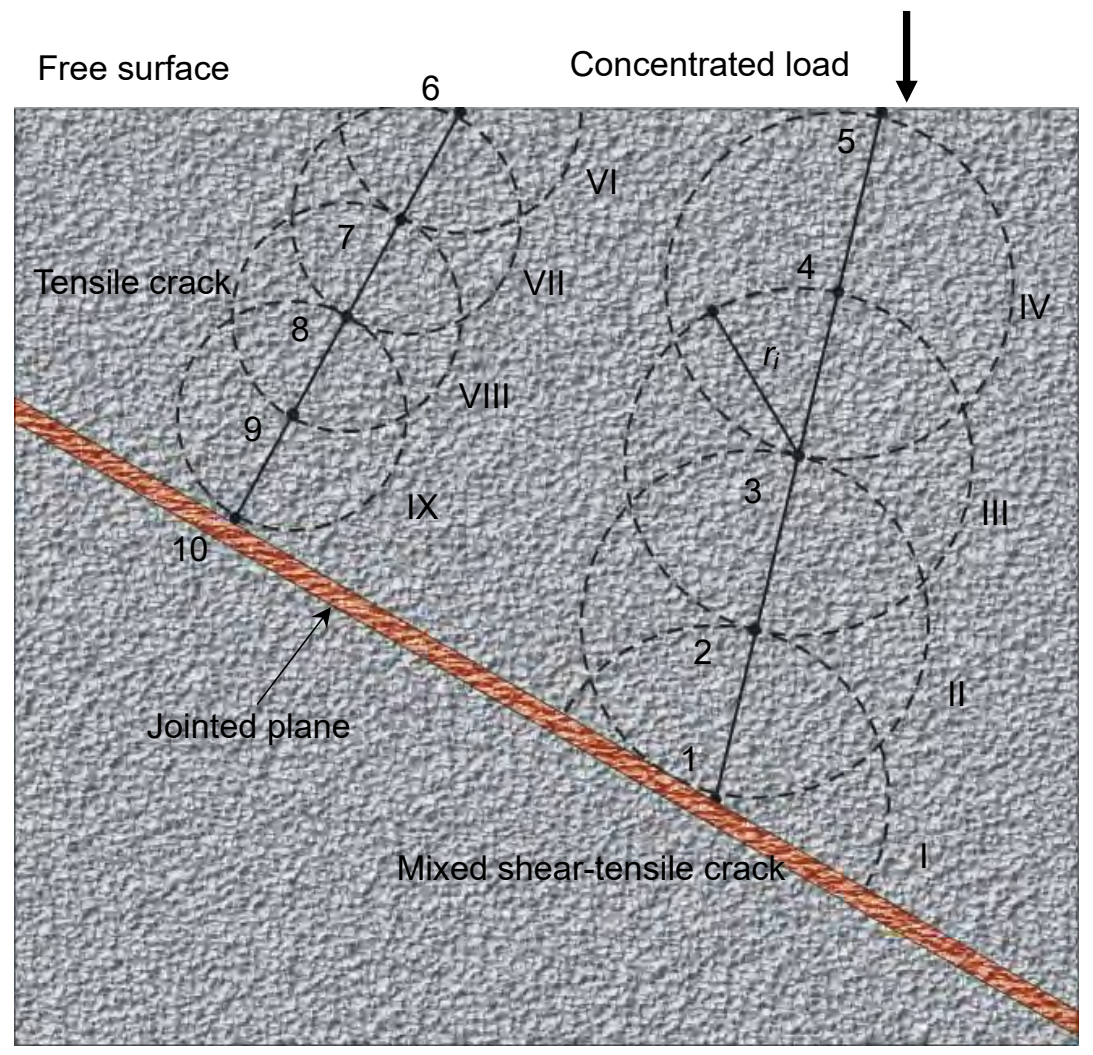

744 Figure 7. The positions for data collection at the mixed shear-tensile crack and tensile

745 crack.

746

747

748

749 
Confidential manuscript submitted to Journal of Geophysical Research: Solid Earth

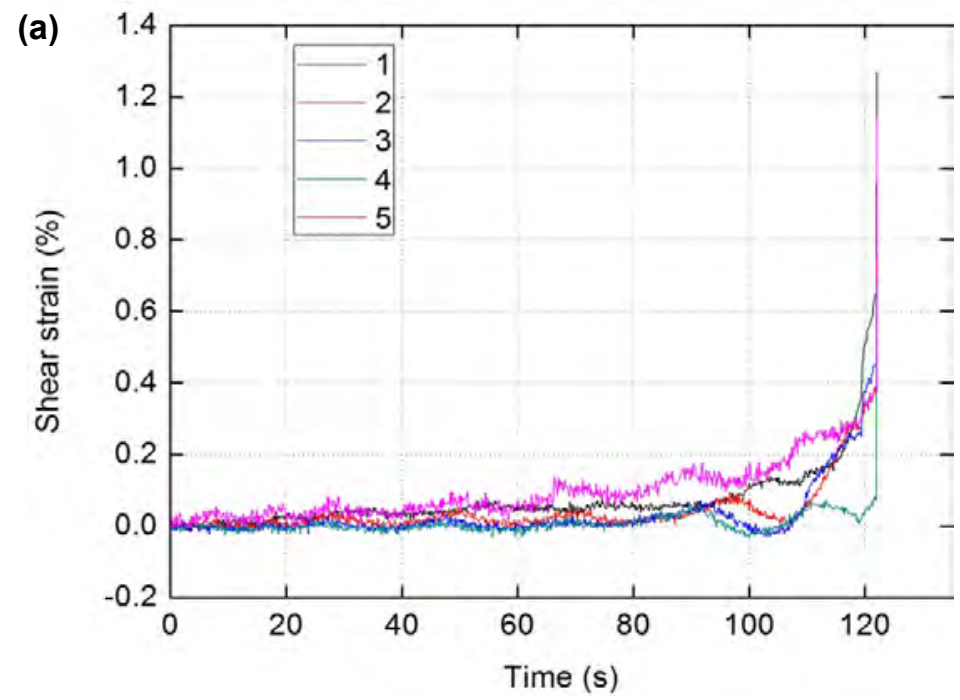

750

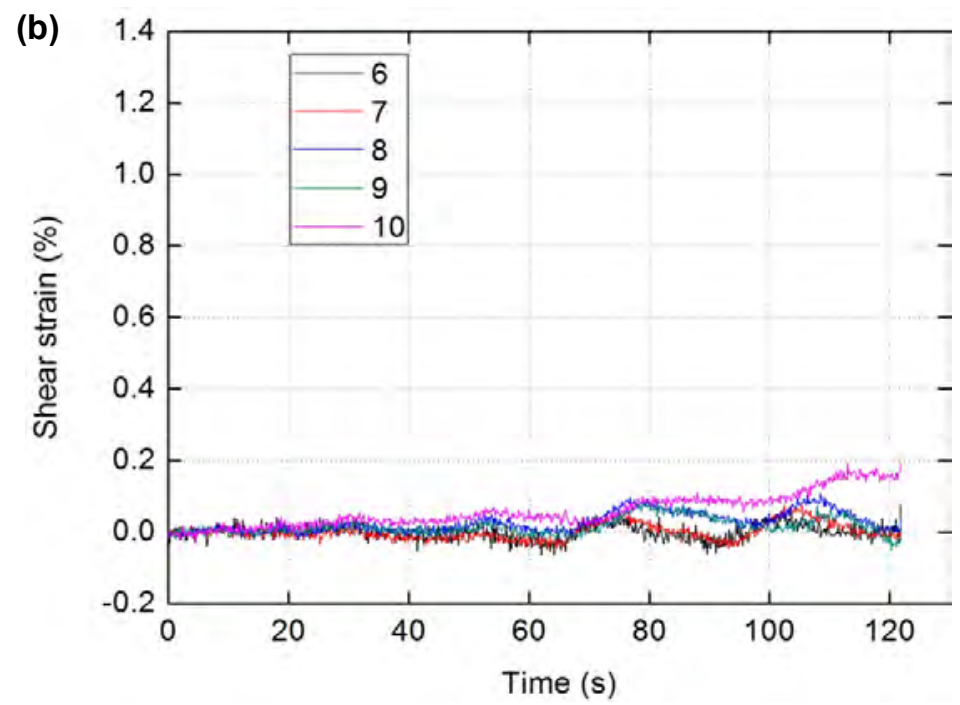

751

752 Figure 8. Variations of shear strain along (a) the mixed shear-tensile crack and (b)

753 tensile crack. 
Confidential manuscript submitted to Journal of Geophysical Research: Solid Earth

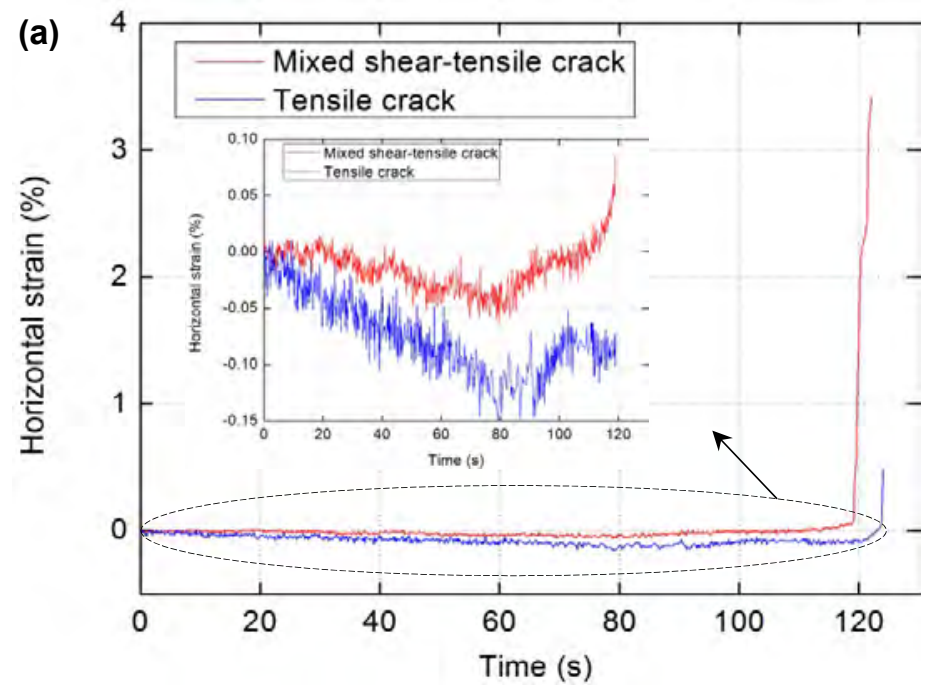

754
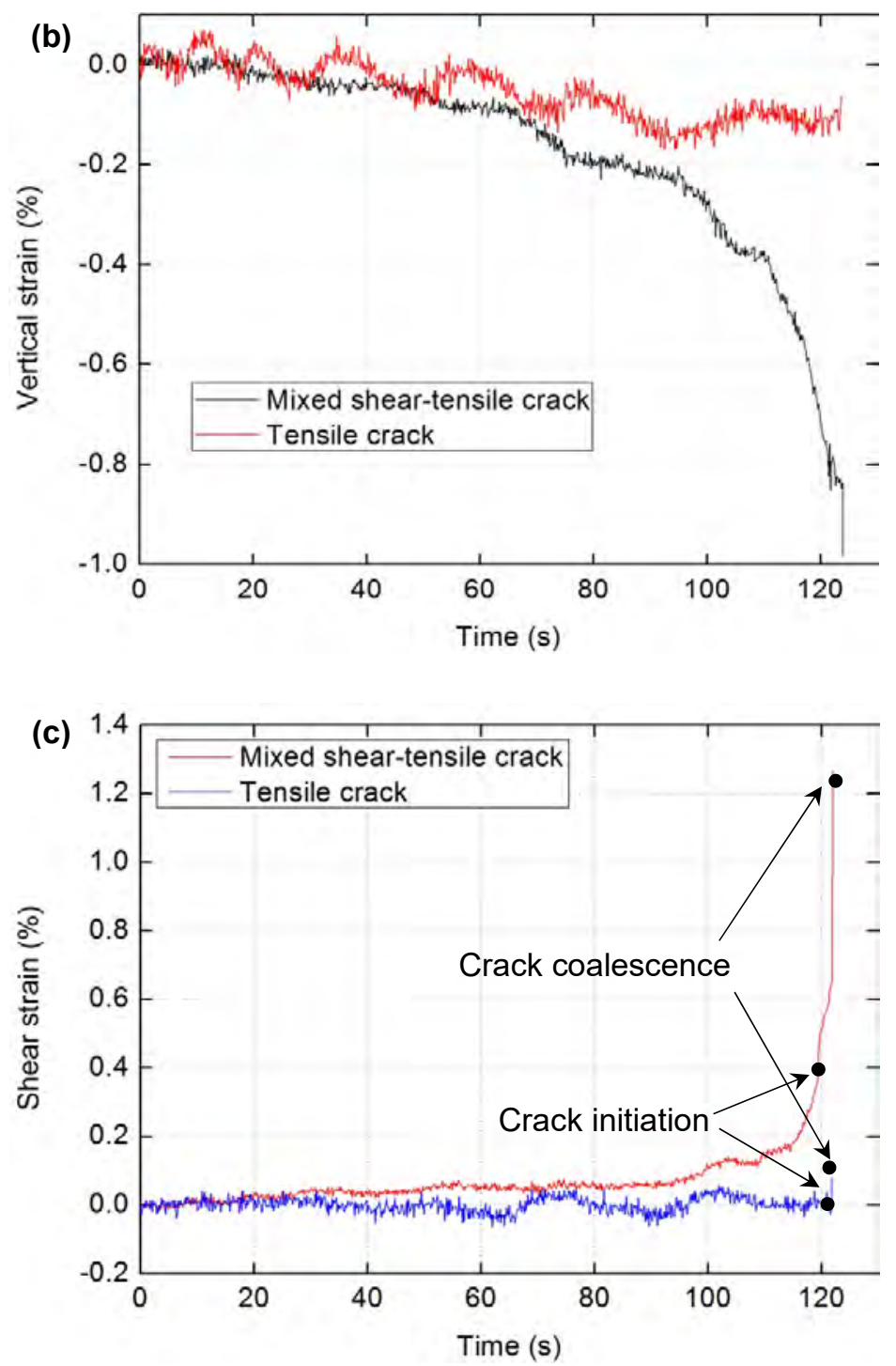
Confidential manuscript submitted to Journal of Geophysical Research: Solid Earth

757 Figure 9. The variations of (a) horizontal strain, (b) vertical strain and (c) shear strain

758 of mixed shear-tensile crack and tensile crack in cracking process.

759

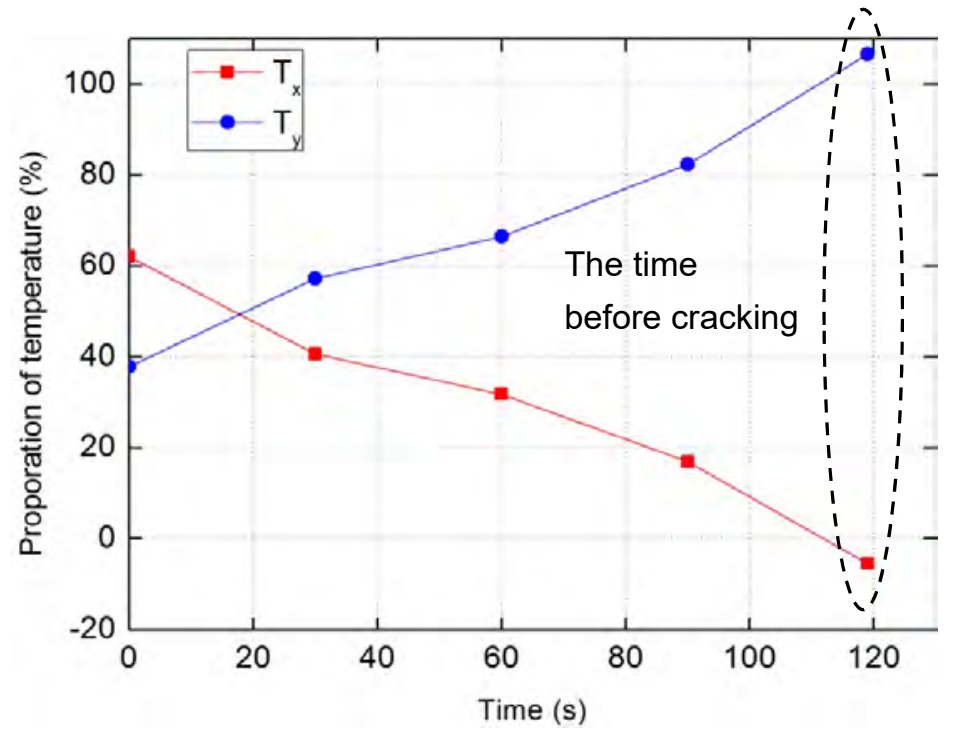

760 Figure 10. The proportion of temperature caused by $\sigma_{x}$ and $\sigma_{y}$ at initiation points for

761 the mixed shear-tensile crack.

762 

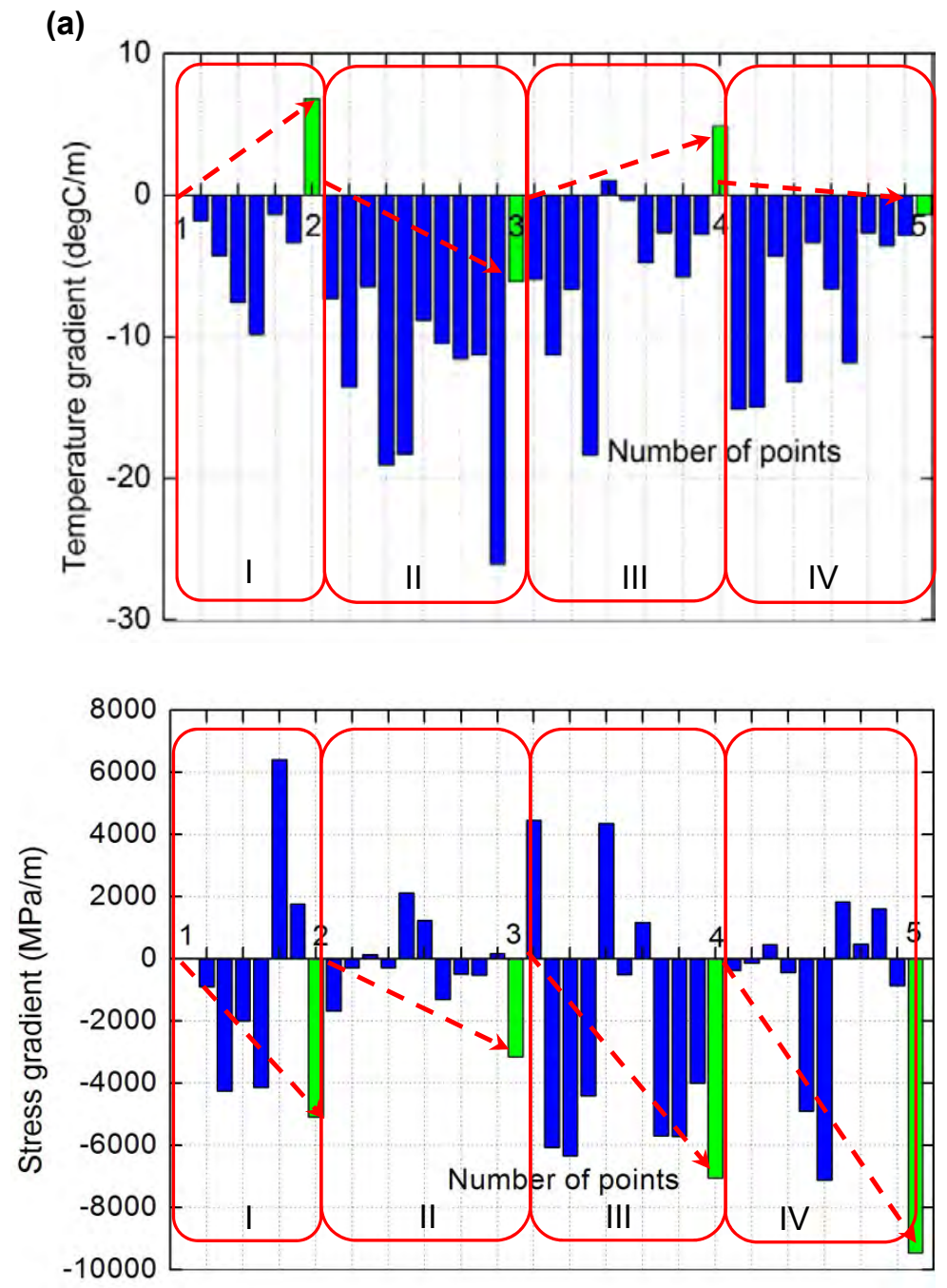
Confidential manuscript submitted to Journal of Geophysical Research: Solid Earth

(b)
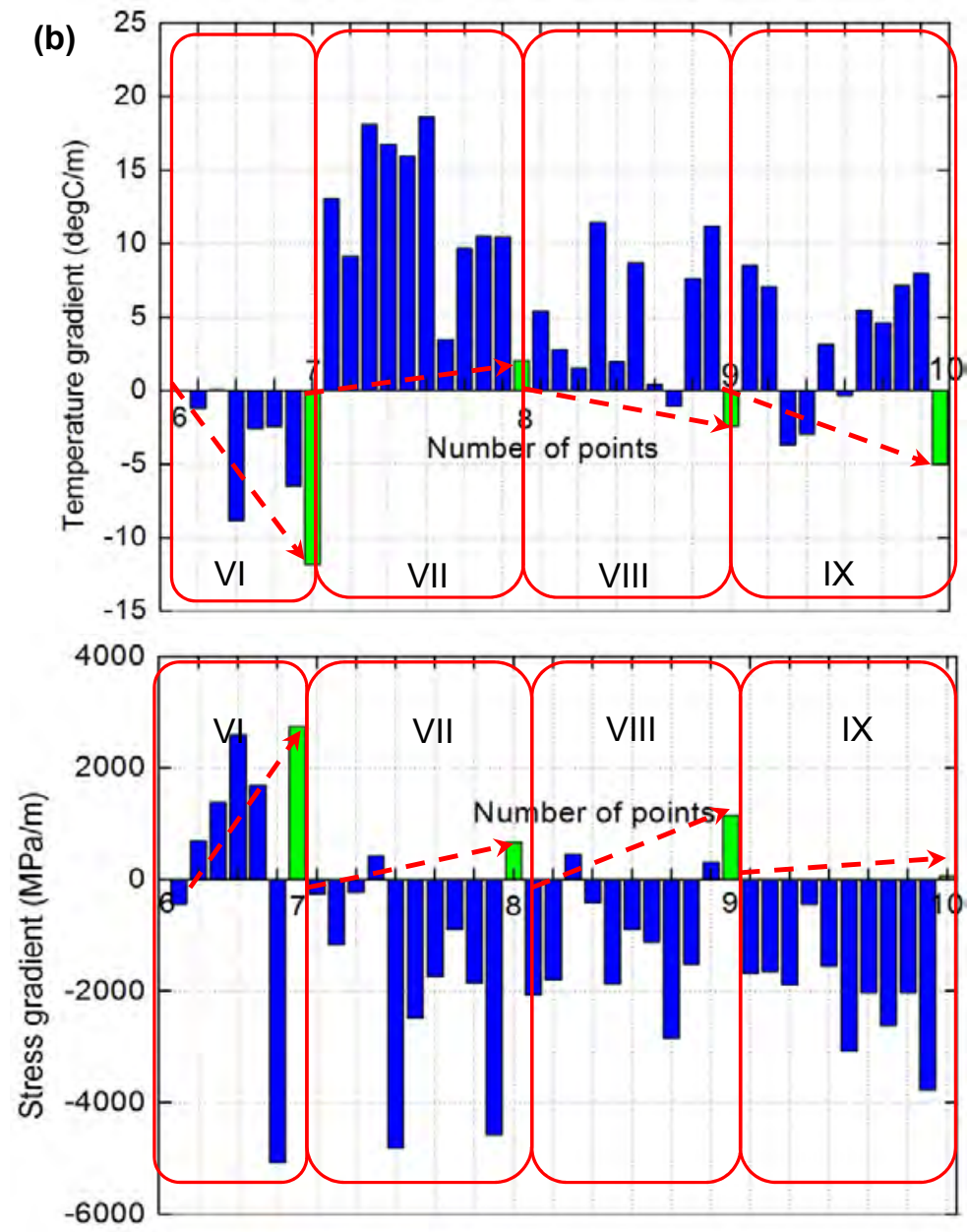

765 Figure 11. Comparisons between average temperature gradients and stress gradients

766 along the cracks, (a) the mixed shear-tensile crack, (b) tensile crack. 
Confidential manuscript submitted to Journal of Geophysical Research: Solid Earth

767

768 Figure 12. Temperature field along the cracks. Healing zone and cooling zone occur

769 along the trajectories of the mixed shear-tensile crack and tensile crack, respectively.

770

771

772

773

774

775

776 
Confidential manuscript submitted to Journal of Geophysical Research: Solid Earth

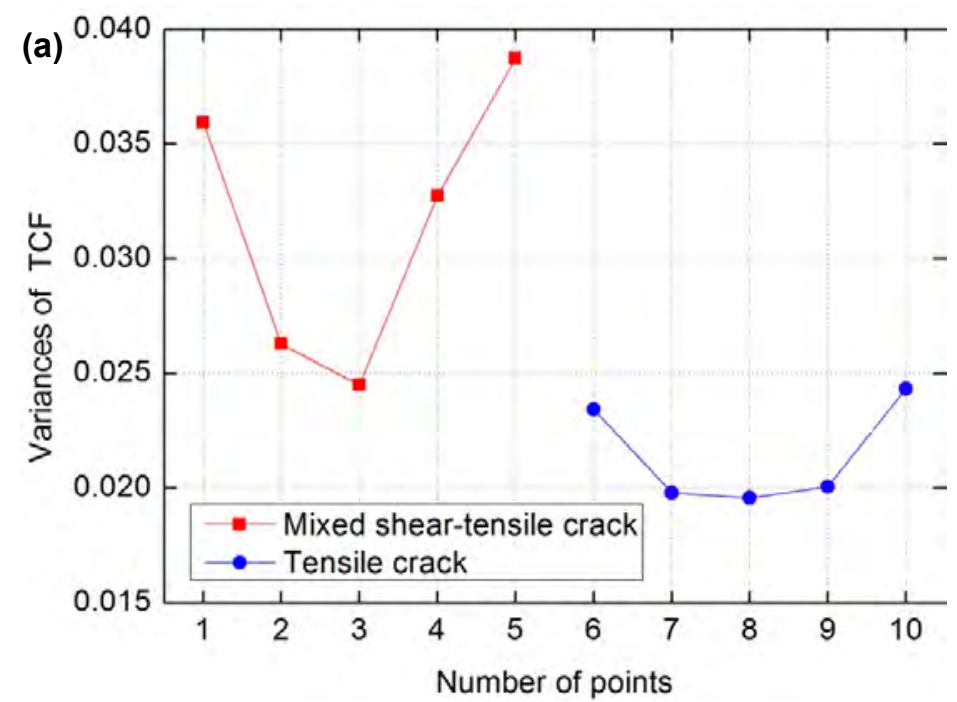

777

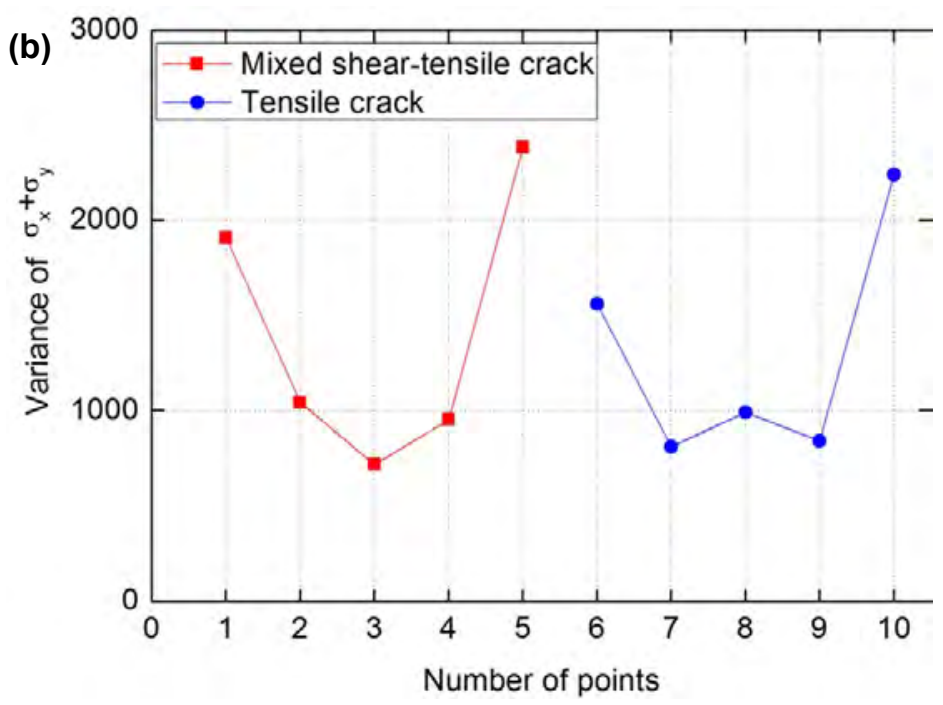

779 Figure 13. Comparisons between (a) variances of temperature concentration factor

780 and (b) $\left(\sigma_{x}+\sigma_{y}\right)$ for the mixed shear-tensile crack and tensile crack.

781

782

783

784 
Confidential manuscript submitted to Journal of Geophysical Research: Solid Earth

786

787

788 Table 1. Physical and mechanical properties of granite and jointed plane

\begin{tabular}{cccccccc}
\hline & $\rho / \mathrm{g} / \mathrm{cm}^{3}$ & $E / \mathrm{GPa}$ & $\sigma_{c} / \mathrm{MPa}$ & $\sigma_{\mathrm{t}} / \mathrm{MPa}$ & $v$ & $c / \mathrm{MPa}$ & $\varphi /$ \\
\hline Granite & 2.6 & 39.8 & 124.7 & 12.3 & 0.21 & 12.5 & 45.0 \\
Joint plane & 2.1 & 5.6 & 29.3 & 1.5 & 0.15 & 0.57 & 32.0 \\
\hline
\end{tabular}

789

790 